\title{
Fragility analysis of concrete elevated water tanks under seismic loads
}

\author{
Amar Aliche, Hocine Hammoum, Karima Bouzelha \\ Department of civil engineering, Mouloud Mammeri University, 15000 Tizi Ouzou, Algeria. \\ amar.aliche@ummto.d\%. \\ hocine.bammoum@ummto.d₹, bttps://orcid.org/0000-0002-1481-6241 \\ karima.bouzelha@ummto.dr.
}

\section{Younes Aoues}

Laboratory for Optimization and Reliability in Structural Mechanics (ex-LMR), INSA Rouen, France. younes.aoues@insa-rouen.fr

Ouali Amiri

Research Institute in Civil and Mechanical Engineering - GeM, Polytech Nantes, France. ouali.amiri@univ-nantes.fr

\author{
Youcef Mehani \\ National Earthquake Engineering Research Center, CGS, Algiers, Algeria \\ mehani_youcef@yahoo.com
}

\begin{abstract}
The design of concrete elevated water tanks involves several kinds of uncertainties. Traditionally, the design of these structures is based on a deterministic analysis. Partial safety factors prescribed in design codes are applied to take into account these uncertainties and to ensure sufficiently safe design. However, this approach does not allow rational evaluation of the risk related to the structural failure and consequently its reliability. In fact, the partial safety factors can lead to over-designed structures; or to under designed structural components leading to a lack of structural robustness. In this study, a probabilistic approach based on Monte Carlo simulations is used to analyze the reliability of elevated water tanks submitted to hazard seismic loading. This reliability approach takes into account mainly two parameters. Firstly, the hydraulic charge in the tank container which is a function of time, and secondly, the hazard seismic loading through the Peak Ground Acceleration is considered as a random variable. Fragility curves depending on seismic zones and soil types are obtained by using the probabilistic approach, where they demonstrate the dominant failure modes that can cause the structural failure with respect to different seismic levels, soil types and water height level in the tank container.
\end{abstract}

\section{open ACcess}

Citation: Aliche, A., Hammoum, H., Bouzelha, K., Aoues, Y., Amiri, O., Mehani, Y., Fragility Analysis Of Concrete Elevated Water Tanks Under Seismic Loads, Frattura ed Integrità Strutturale, 57 (2021) 93-113.

Received: 03.04 .2021

Accepted: 21.05.2021

Published: 01.07 .2021

Copyright: (C) 2021 This is an open access article under the terms of the CC-BY 4.0, which permits unrestricted use, distribution, and reproduction in any medium, provided the original author and source are credited.

KEYWORDS. Reliability; Seismic acceleration; Hydraulic load; Failure; 


\section{INTRODUCTION}

$\mathrm{T}$ he concrete water tanks are considered as hydraulic structures and are classified as important facilities among constructions. In many developed and developing countries, water tanks play an important role in the water supply networks. In Algeria, due to the demographic explosion, the number and the size of these concrete water tanks became increasingly important. After a major earthquake, it is vital that these potable water storage structures should be preserved, because they play a key role in the organization of the first aid. Concrete elevated tanks are considered as heavy structures where the largest part of their weight is concentrated in the upper part at a given height. Their dynamic behaviour has been the subject of several researches in order to improve their design and their strength against strong seismic loads.

The first published work in this field was conducted by Hoskin and Jacobsen [20] which was based on Westergaard [42] work focused on rigid rectangular gravity dams, considering theoretical and experimental studies in order to evaluate developed hydrodynamic pressures in rectangular tanks when subjected to seismic excitation. Ruge [38] have carried out many results on concrete elevated tanks, studied experimentally the effects of an earthquake on this specific category of tanks, drawing out the fact of the interaction between fluid and structure. Subsequently, Jacobsen [24] and Jacobsen and Ayre [25] have studied experimentally and analytically the dynamic response of rigid cylindrical tanks. Werner and Sundquist [41] extended conclusions of Jacobsen's works to tanks with rectangular, semi-circular, triangular and spherical forms. Graham and Rodriguez [13] provided a detailed analysis of convective hydrodynamic pressures related to fluid sloshing and impulsive in rectangular tanks. In the end of 1950s and the beginning 1960s, the works of Housner [21, 22] allowed to carry out the simplified analytical method, modelling the tank with an equivalent two degree of freedom system, concentrating the total mass at two points (impulsive and convective). This method gives an analytical solution to the problem of the seismic response of liquid storage tanks. Later in the 1970s, Epstein [10], based on Housner's model[22], has developed formulas and design curves in order to estimate the bending and overturning moments in rectangular and cylindrical tanks subjected to a seismic excitation. Hunt and Priestley [23] proposed a new computing approach of tanks (cylindrical and rectangular), taking into account both impulse and oscillation phenomena.

From the 1980s, Haroun [15-19] published a series of works in collaboration with Housner concerning the dynamic behaviour of cylindrical and rectangular tanks, including the effect of the liquid on the wall structure, taking into account the deformation of the structure. Davidovici and Haddadi [7] presented and compared several methods developed by the above mentioned authors, such as the method of Jacobsen and Ayre with that of Hunt and Priestley applied to cylindrical tanks, and the method of Graham and Rodriguez with that of Hunt and Priestley established for rectangular tanks.

Park et al. [34] provided a robust numerical method based on the boundary and finite elements method. The first is used to calculate the hydrodynamic pressure taking into account the sloshing, while the second is used to evaluate the response of the structure taking into account the fluid-structure interaction.

Livaoglu et al. [28-30] and Sezen et al. [40] have conducted several studies that have examined the liquid-structure-soil interaction, considering the embedment effect, the soil type and the soil-structure interaction on the seismic behaviour of the tank. These works were carried out on different types and sizes of structures.

Hammoum et al. [14] have been interested in the hydrodynamic analysis of circular concrete water tanks on the basis of the model of Housner. They proposed a model taking into account the hydrodynamic effect, with using the response spectrum method according to the Algerian seismic code [37].

Akbari et al. [3] have studied the seismic behaviour of unanchored steels tanks placed on the ground with a focus on the bottom sheet uplift mechanism of the structure under the effect of hydrodynamic loads. Two models of accelerograms were used in this study namely the seismic records of the 1940 El Centro and 1994 Northridge earthquakes.

The deterministic methods mentioned above, don't consider several kinds of uncertainties related to material properties, loading and model approximations which are involved in the design of concrete tanks.

The rational approach to design reliable and economical structures is based on probability theory. A new methodology based on the structural reliability theory which takes into account these uncertainties. Thus, we notice a growing interest of the scientific community of civil engineering for the application of probabilistic approaches in the structural analysis and design [27].

Peyras et al. [35] have proposed a methodology of coupling the dependability method (FMEA) with the reliability approach in order to assess the structural safety of dams. The work of Lupoi et al. [31] focused on the development of 
a probabilistic method of seismic assessment which is able to manage the physical complexity of the dam-foundation damage and uncertainties regarding the structural data and external actions. Gholizad et al. [12] have proposed in the field of offshore structures, an assessment method of reliability, which considers different failure scenarios of fatigue structural components. This approach provides more detailed information on the fatigue behaviour of different structure components.

Few works have used the probabilistic approaches for the storage tanks reliability assessment. Berahman et al. [5] have used the probabilistic approach to estimate the seismic fragility of steel storage tanks in the petroleum industry. The probabilistic model is developed on the basis of several failure modes, such as the elephant foot bucking and welding failure at the connection between the bottom plate and shell. Sani et al. [39] have studied the reliability of an underground reinforced concrete rectangular water tank considering three failure modes (bending, shear and torsion), where the reliability analysis is carried out by the First Order Reliability Method (FORM) approach. Moreover, Môller et al. [33] have proposed a probabilistic approach to design the circular section of the supporting system of reinforced concrete elevated tanks, corresponding to a target probability of failure. Phan et al.[36] investigate the seismic vulnerability of elevated steel storage tanks rested upon reinforced concrete columns through a probabilistic seismic assessment approach. In their study, a probabilistic seismic demand models incorporating uncertainty parameters for the tank components are established. Then, relevant fragility curves, which present the most likely damage states of the tank components are proposed. Aliche et al. [4] have used a probabilistic approach is used to analyse the reliability of cylindrical water tanks fully anchored to the rigid foundation and submitted to hazard seismic loading. The state functions used in the reliability model are those related to the various phenomena observed on field including sliding applied at the base of the tank, the overturning, wall stresses and sloshing effect of free surface water. Fragility curves depending on the seismic zone and site conditions are obtained by using the probabilistic approach, where they demonstrate the dominant failure modes that can cause the structural failure combined to different seismic levels, site effect and the hydraulic load.

In the present work, which is a continuation of the work mentioned above, we are interested in the analysis of the seismic reliability of another type of storage tank that is a RC water storage elevated tank. This kind of structure is considered to be very complex in the design, study under seismic action, due to the concentration of the greater portion of the weight in the upper part of its height. The seismic response of the reservoir is obtained by Housner model [21, 22], considering limit state functions related to the ultimate and serviceability limit states of the concrete elevated tank under seismic analysis. Monte Carlo simulation is used to carry out the reliability analysis [27], where two types of variables are considered, firstly the hydraulic charge in the tank container, which is a function of time, secondly, the hazard seismic loading.

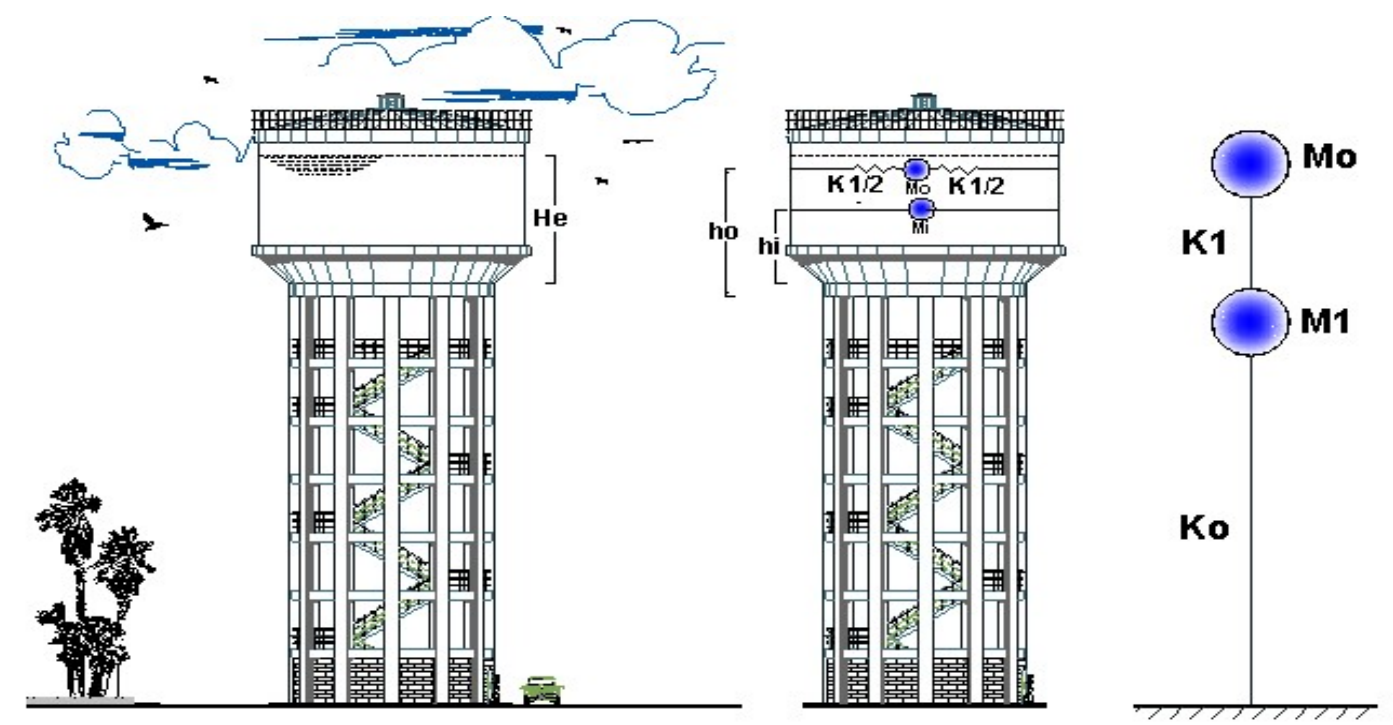

Figure 1: Elevated tank, equivalent mechanical system and mathematical model.

\section{DETERMINISTIC MODEL OF SEISMIC RESPONSE ANALYSIS OF AN ELEVATED TANK}

$\mathrm{I}$ $\mathrm{n}$ the case of an elevated water tank, we cannot consider the container as being rigidly related to the soil and therefore, undergoing the same acceleration than this latter, as that is the case with a tank placed on the ground. Indeed, when the container is on the top of a RC pedestal (supporting structure), we must consider its flexibility. 
Approached calculation by the Housner method consists in decomposing the liquid action in two actions, an impulsive action causing impulsive efforts and convective action causing convective efforts [22].

The mathematical model adopted for the elevated tank (Fig. 1) is obtained by considering the mass $\mathrm{M}_{0}$ connected to the structure by a rod of the same stiffness $K_{1}$, forming a coupling with the mass $M_{1}$, representing the masses of impulse of the tank, noted $\mathrm{Mi}$, as well as a part of the pedestal. The mass $\mathrm{M}_{1}$ is connected to the ground by a rod representing the pedestal of constant stiffness $\mathrm{K}_{0}$. The system is therefore at two degrees of freedom as described by the mathematical model presented in Fig. 2. Readers interested in more details on this method can consult the reference [14].

\section{Probabilistic ANALYSIS OF FAILURE RISK OF AN ELEVATED TANK}

\section{Probabilistic context}

o quantify the failure risk of a concrete elevated tank, by loss of stability at the ultimate limit state and by loss of strength at the serviceability limit state, it is appropriate to define the different limit state functions $G$ $(\{\mathrm{X}\})$, which define their behaviour. These functions define the failure and the safety domains. A limit state function $\mathrm{G}(\{\mathrm{X}\})$ can be written as follows [27]:

$$
\mathrm{G}(\{X\})=\mathrm{R}(\{X\})-\mathrm{S}(\{X\})
$$

where:

$G(\{X\})$ : limit state function of the structure $(G>0$ : safety domain, $G=0$ : limit state function, $G<0$ : failure domain), $\{X\} \quad$ : random vector constituted by random variables $\mathrm{x}$,

$R(\{X\})$ : strength of the structure related to a considered failure mode,

$\mathrm{S}(\{X\})$ : active loading.

The collapse of the structure is related to the exceeding of the limit state $G(\{X\})=0$, and reliability analysis consists to calculate the probability of failure defined by:

$$
P_{f}=P(G(\{X\}) \leq 0)
$$

The probability of failure is defined by:

$$
\mathrm{P}_{\mathrm{f}}=\int_{\mathrm{D}_{\mathrm{f}}} f_{X}(\mathrm{x}) \mathrm{dx}
$$

$\mathrm{D}_{\mathrm{f}}$ is the failure domain defined by: $\mathrm{D}_{f}=\{\mathrm{x} \in \mathrm{R} / \mathrm{G}(x) \leq 0\}$

$f_{X}(\mathrm{x})$ is the probability density function of the random vector $\{\mathrm{X}\}$ constituted by the random variables $\mathrm{x}_{\mathrm{i}}$, whose realizations are $\{\mathrm{X}\}=\left\{\mathrm{x}_{1}, \mathrm{x}_{2}, \ldots, \mathrm{x}_{\mathrm{n}}\right\}^{\mathrm{t}}$.

\section{Failure modes and limit state functions}

The deterministic model presented in section 2 allows estimating the dynamic response of a concrete elevated tank under seismic loading. The structure is considered as an inverted pendulum in which the mass is concentrated at the top of the supporting system. The behaviour of the bracing system (supporting system) can reach its ultimate capacity before the other components (dome, wall, etc.).According to Eurocode8 [6], the stability of a tank under seismic action shall be verified with the ultimate limit state and serviceability limit state. In the following, we present the five limit state functions to be analysed in our study.

\section{Ultimate limit state of overall stability to overturning}

According to Eurocode 8 [6], under the seismic action effect at ultimate limit state, the overall stability of the tank can be lost by overturning. The overturning moment $\mathrm{M}_{\mathrm{r}}$, where this moment is due to the seismic action shall be calculated regarding to the level of contact soil-foundation. The stabilizer moment $\mathrm{M}_{\mathrm{s}}$ is calculated by taking into account the weight of the structure, of the foundation and eventually the weight of the backfill on the foundation. The 
justification in this limit state consists to verify that the stabilizer moment of the structure is greater than the overturning moment. The performance function $\mathrm{G}_{1}$ associated with this limit state is represented by the following stability condition:

$$
G_{1}: M_{s}-M_{r}
$$

\section{Ultimate limit state of overall stability to sliding}

According to Eurocode8 [6], under the effect of seismic action to the ultimate limit state, the overall stability of the tank can also be lost by slipping. Sliding resistance is calculated assuming that the failure occurs in the soil and not at the interface of foundation-soil. For this failure mode, the corresponding limit state function is given by

$$
\mathrm{G}_{2}: \mathrm{N}_{\mathrm{u}} \cdot \operatorname{tg} \varphi+\mathrm{c} \cdot \mathrm{A}-\mathrm{F}_{b}
$$

$\mathrm{N}_{\mathrm{u}}$ is the vertical component of ultimate loads considering the total weight of the tank, the weight of the foundation and eventually the weight of the backfill on the foundation. $\mathrm{C}$ and $\varphi$ are respectively the cohesion and the internal angle of friction of the foundation-soil. A, denotes the area of the foundation part in contact with the ground and $F_{h}$ means the resultant of the horizontal seismic forces.

\section{Serviceability limit state of tensile stress in steel reinforcement}

The tensile stresses $\sigma_{\text {st }}$ in steel reinforcement depend on the state of opening cracks in the concrete. According to Fascicule 74 [11] for supporting system of elevated reinforced concrete tank, cracks are considered as highly prejudicial. It is necessary to ensure that stresses in reinforced steel satisfy the following inequality:

$$
\sigma_{s t} \leq \bar{\sigma}_{s t}=0,80 \cdot \min \left\{\frac{2}{3} \cdot f_{e} ; \max \left(\frac{f_{e}}{2} ; 90 \sqrt{\eta \cdot f_{t j}}\right)\right\}
$$

The failure related to the loss of tensile strength corresponds to the appearance of cracks in the tank supporting system, the function of limit state is given as follows:

$$
G_{3}: \bar{\sigma}_{s t}-\sigma_{s t}
$$

Serviceability limit state of compression stress in concrete

According to the Fascicule 74 [11], the compression stress $\sigma_{b c}$ in concrete is limited to the smallest of following values:

$$
\sigma_{b c} \leq \bar{\sigma}_{b c}=\min \left\{\frac{\mathrm{e}+0,55}{3} \cdot \mathrm{f}_{\mathrm{c} 28} ; \frac{130 \cdot \mathrm{e}}{\mathrm{D}_{\mathrm{int}}} \cdot \mathrm{f}_{\mathrm{c} 28}^{1 / 3} ; 0,60 \cdot \mathrm{f}_{\mathrm{c} 28}\right\}
$$

where (e) is the wall thickness of the tank supporting system (tower).

The limit state function related to the failure regarding to the compression strength of the concrete, is given by the relation:

$$
G_{4}: \bar{\sigma}_{b c}-\sigma_{b c}
$$

\section{Sloshing effect}

Under to a seismic action, in partially filled tanks, a part of the fluid is set in motion; which leads to the formation of surface wave, leading to the creation of stresses which cause damage to some of its components (wall and dome).A freeboard must be provided to prevent damage to the dome due to wave effect, or to prevent liquid overflow when the tank has no rigid roof.

According to Eurocode8 [6], the predominant contribution to the wave height of the sloshing is provided by the first fundamental mode, and the expression of the wave peak can be assessed by:

$$
\mathrm{d}_{\max }=0.84 \frac{\mathrm{S}_{\mathrm{ai}}}{\mathrm{g}} \mathrm{R}
$$


where, $\mathrm{S}_{\text {ai }}$ and $\mathrm{R}$ designate respectively the seismic acceleration and the internal radius of the tank.

$\mathrm{H}$ is the height between the water free level and the cover dome. This height varies according to the water level $\mathrm{H}_{\mathrm{e}}(\mathrm{t})$ useful in the tank container at a given time $(\mathrm{t})$. It can be written as follows:

$$
\mathrm{H}=H_{\max }+H_{0}+\mathrm{H}_{\mathrm{cs}}-\mathrm{H}_{\mathrm{e}}(\mathrm{t})
$$

As illustrated in Fig.2, $\mathrm{H}_{\max }$ denotes the water height in the tank container to the level of the overflow; $\mathrm{H}_{0}$ represents the height between the overflow and the upper beam of the tank. $\mathrm{H}_{\mathrm{cs}}$ denotes the height of the upper beam of the tank.

The failure of the limit state function by sloshing is given by the relation:

$$
\mathrm{G}_{5}: \mathrm{H}-\mathrm{d}_{\max }
$$

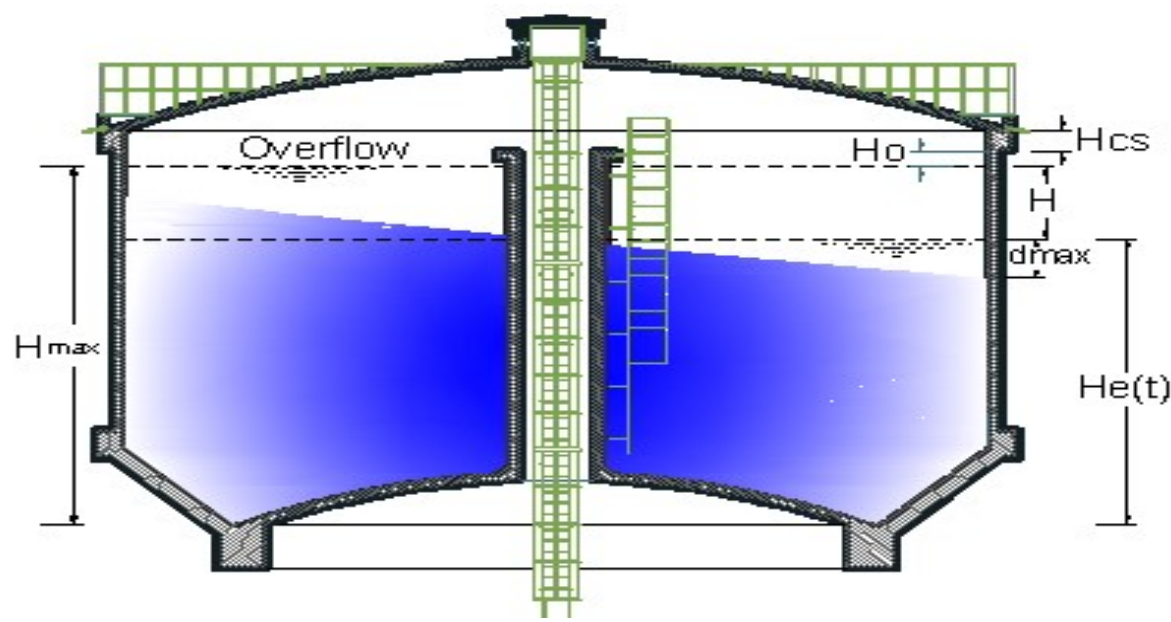

Figure 2: Description of different heights in the tank container at a specific time $(\mathrm{t})$.

\section{Identification of considered variables}

Two parameters related to the seismic action and the hydraulic loading are considered in this study.

\section{Random seismic loading}

In several seismic design codes, the dynamic structural response to earthquake actions is carried out with spectral approach. The response spectrum is built from several accelerograms, where they are affected by numerous uncertainties. These uncertainties are related to the measure of the earthquake acceleration at a given location. In order to identify these uncertainties, seismic codes (RPA, Eurocode, ASCE, etc...) are based on the feedback from past earthquakes to perform the design spectrum. To study the seismic behaviour of storage tanks, it is important to consider the uncertainties related to seismic accelerations $S_{a}$ drawn from the design spectra. This parameter may be considered as a random variable modelled by a probability distribution function.

To identify the type of probability distribution, a statistical analysis based on Chi-2 type tests [2] is performed. Forty five (45) accelerograms of the earthquake of 21 May 2003 of Boumerdes (Algeria) are used for the statistical analysis. These accelerograms are recorded by various accelerographs installed by the National Earthquake Engineering Research Centre (CGS) in the central region of Algeria (Fig.3). Fig. 4 shows an example of an accelerogram recorded on the site of Kheddara Dam (50 kms East of Algiers).

The Statistical hypothesis test consists to find the appropriate probability distribution that can be fit the sample of seismic acceleration peaks. Fig. 5 shows the histogram of seismic acceleration peaks, where four probability distributions (lognormal, Gamma, Gumbel and Exponential) are superposed.

To confirm or reject the null Chi- 2 test hypothesis, the calculated value $\chi^{2}$ is compared to the value given in the Chi-2 table. The results of the adjustment test given in Tab. 1, show that the Gumbel distribution is accepted to model the distribution of seismic acceleration peaks of the central region of Algeria. The main reason is that the value of the statistic test for the Gumbel distribution is well below the critical value. According to Tab. 1, the Gumbel distribution has the smallest value of the statistic test for seismic acceleration peaks sample. Hence, based on the chi-squared test, the Gumbel distribution is the best-fitted distributions for the generated sample. 


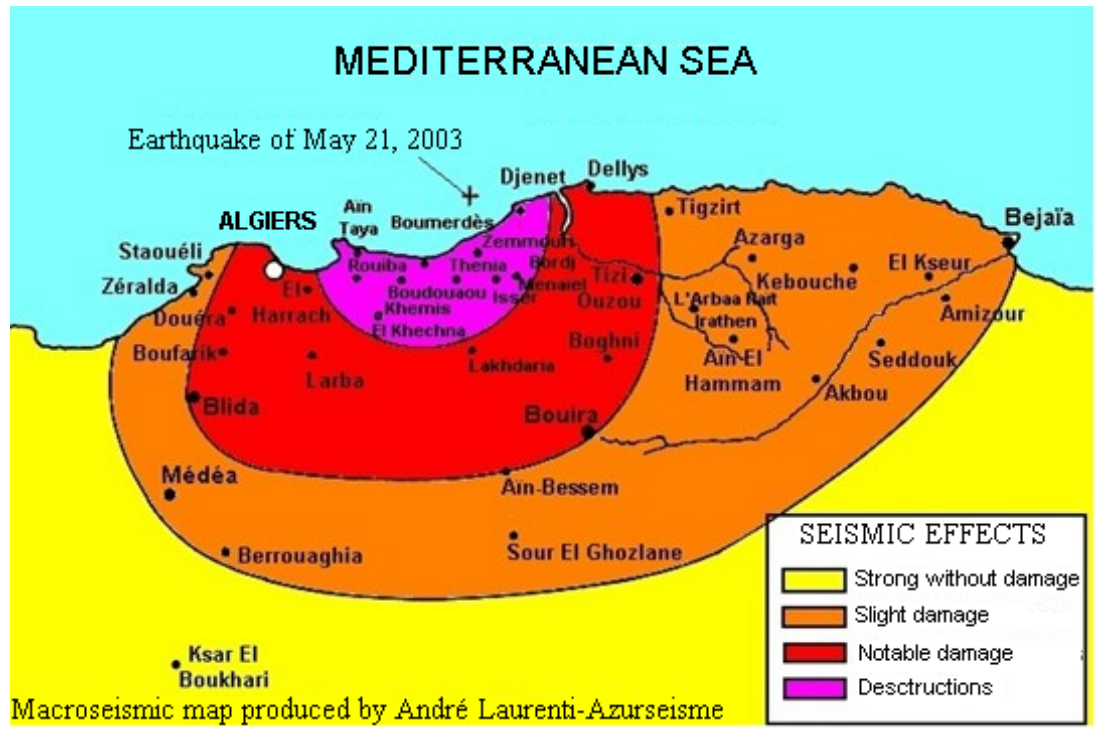

Figure 3: Macroseismic map of the central region of Algeria (by André Laurenti, Azurseisme.com)

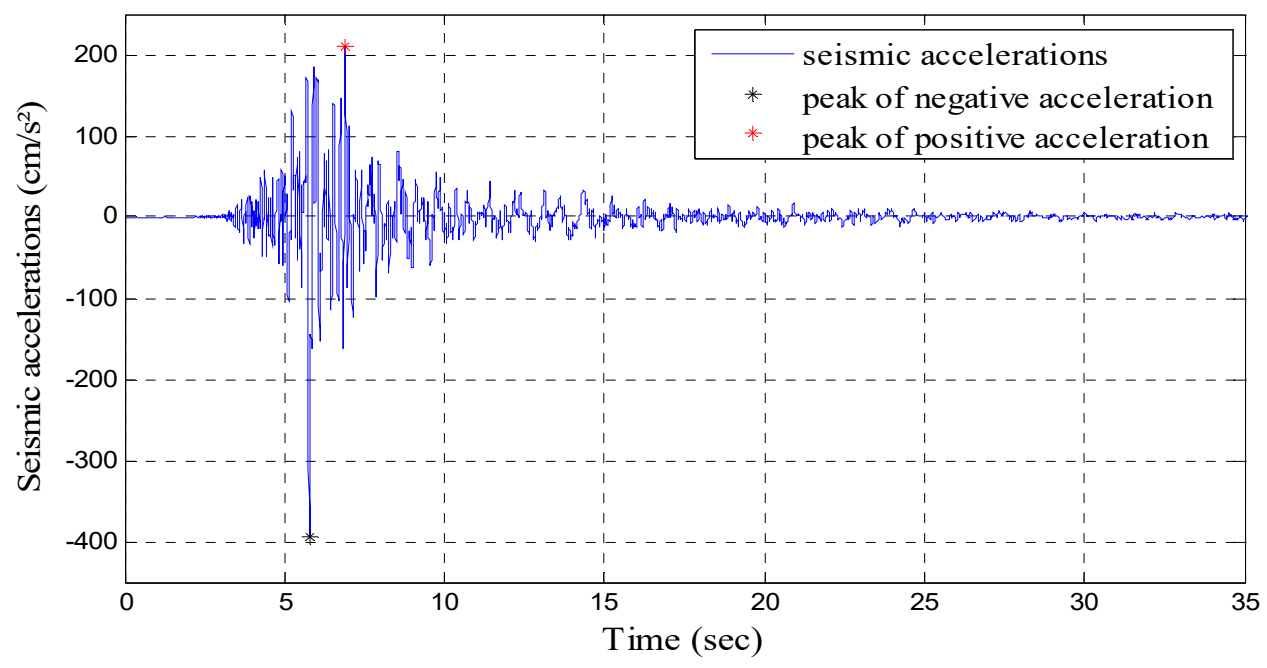

Figure 4: Recorded accelerogram on the site of Kheddara dam (CGS).

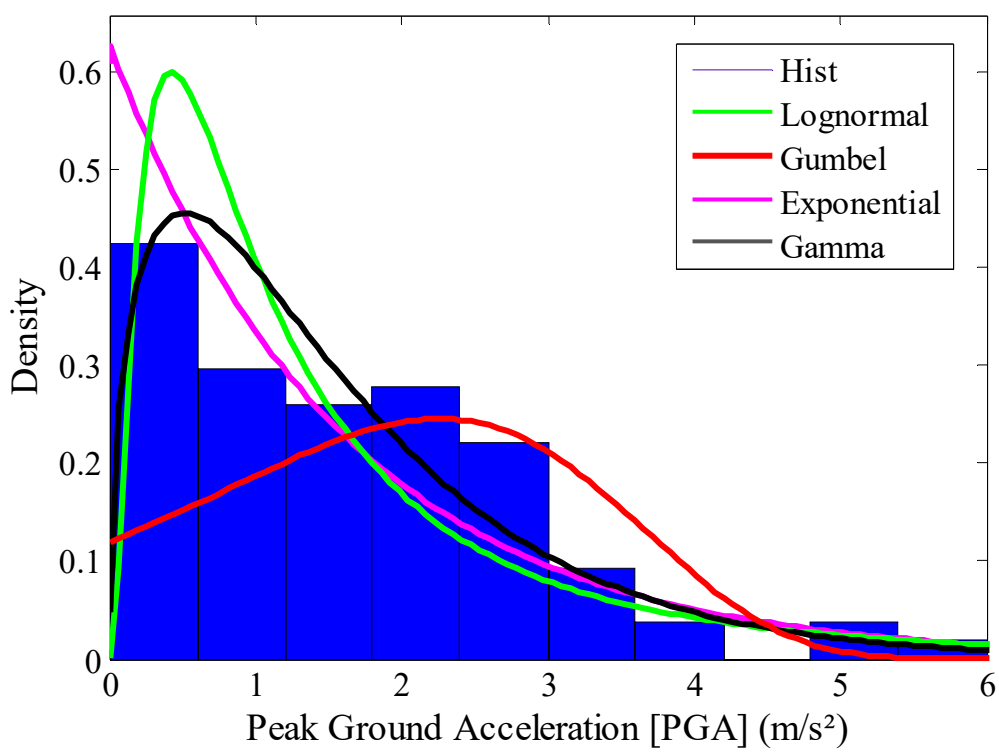

Figure 5: Histogram of acceleration peaks. 


\begin{tabular}{|c|c|c|c|c|}
\hline $\begin{array}{l}\text { Distribution } \\
\text { laws }\end{array}$ & Parameters & $\begin{array}{l}\text { Statistical test } \\
\chi_{\text {observed }}^{2}\end{array}$ & Critical value $\chi_{\text {theoritical }}^{2}$ & $\begin{array}{l}\text { Test } \\
\text { result }\end{array}$ \\
\hline lognormal & $\begin{array}{c}\mu=0.0894 \\
\sigma=0.976\end{array}$ & 18.73 & & Rejected \\
\hline Gumbel & $\begin{array}{l}\mu=2.254 \\
\sigma=1.497\end{array}$ & 6.30 & 7.81 & Accepted \\
\hline Gamma & $\begin{array}{l}A=1.4771 \\
B=1.0774\end{array}$ & 8.10 & & Rejected \\
\hline Exponential & $\mu=1.591$ & 13.61 & & Rejected \\
\hline
\end{tabular}

Table 1: Analysis of the adjustment degree of distribution laws by the adequacy test chi-2.

Fig. 6, shows the cumulative probability function of the Gumbel distribution that confronts empirical acceleration peaks to the theoretical peaks of the considered distribution. The obtained result shows that the greater numbers of the points are aligned along the theoretical cumulative probability line, where some points at the lower end.

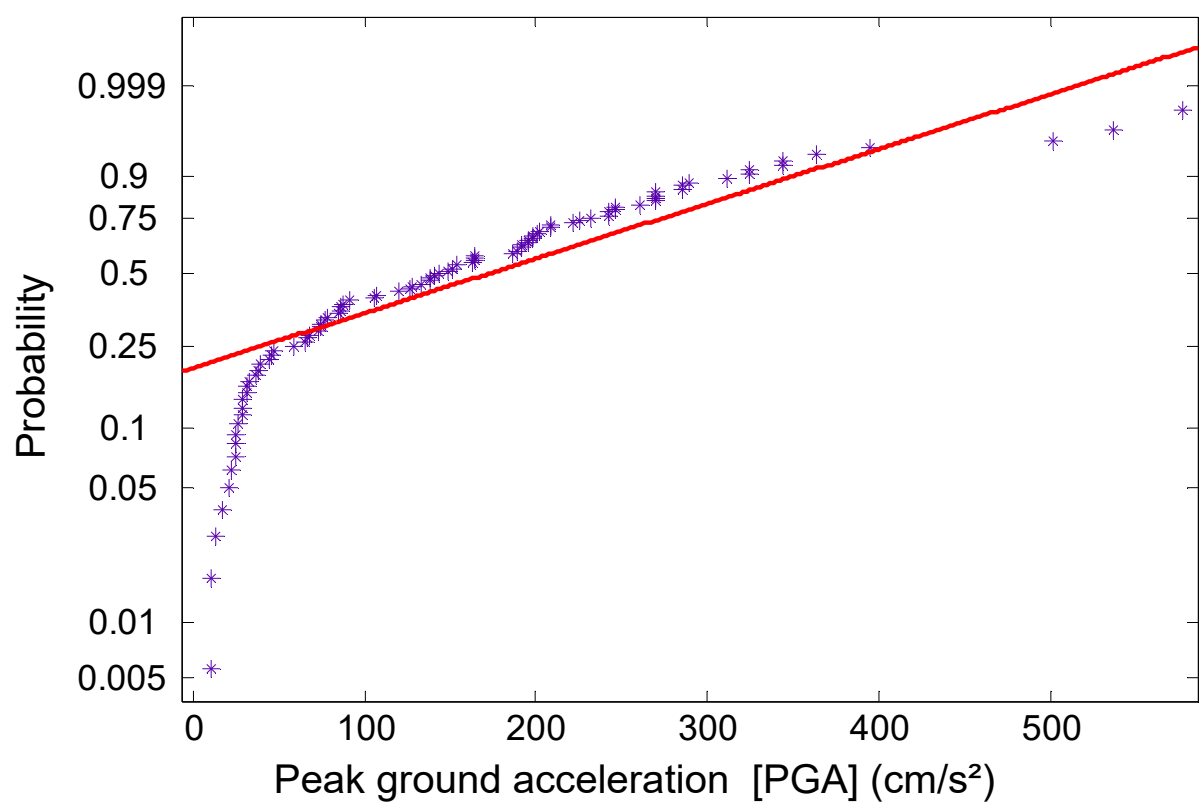

Figure 6: Comparison of empirical acceleration peaks of the considered earthquake to theoretical peaks of the Gumbel distribution law.

\section{Hydraulic loading}

The water tanks present a variable storage capacity (Tab. 2), where the stored water height varies during the day. If we consider a continuous water supply with an average hourly flow rate of distribution $\mathrm{Q}_{\mathrm{h}}$, the maximum daily distribution flow rates can be modelled in the form of diagram capacity as shown in Fig.7 [9]. The volume of stored water in the tank varies during the day and it reaches a theoretical maximum volume of $10 \mathrm{Q}_{\mathrm{h}}$.

\begin{tabular}{ll}
\hline Time slot & Hourly flow rates of consumption \\
From 6 am to $7 \mathrm{am}$ & $\mathrm{Q}_{\mathrm{h}}$ \\
From 7 am to $11 \mathrm{am}$ & $3.5 \mathrm{Qh}_{\mathrm{h}}$ \\
From 11 am to $4 \mathrm{pm}$ & $0.4 \mathrm{Qh}_{\mathrm{h}}$ \\
From 4 pm to $6 \mathrm{pm}$ & $2 \mathrm{Qh}_{\mathrm{h}}$ \\
From 6 pm to $10 \mathrm{pm}$ & $0.5 \mathrm{Qh}$ \\
From 10 pm to $6 \mathrm{am}$ & $0.125 \mathrm{Qh}_{\mathrm{h}}$ \\
\hline
\end{tabular}

Table 2: Hourly flow rates of consumption at different times of the day. 
If we consider that $\Omega$ is the internal cross section of the tank container, we deduce that the daily variation of the height of water $\mathrm{H}_{\mathrm{e}}(\mathrm{t})$ in the tank can be put as a function of the tank capacity $\mathrm{V}(\mathrm{t})$ as a function of time, in the form:

$$
H_{e}(t)=\frac{V(t)}{\Omega}
$$

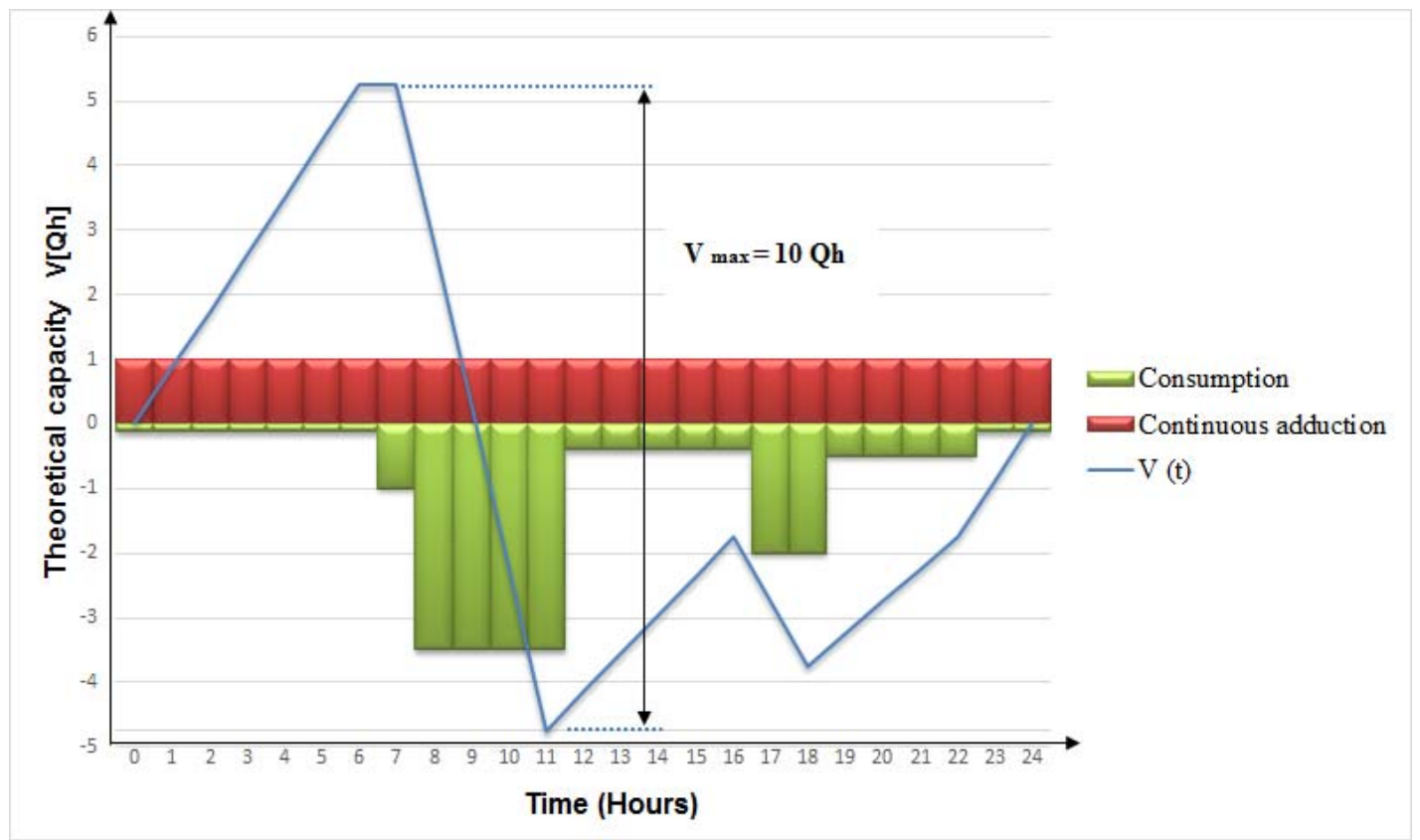

Figure 7: Theoretical capacity in continuous water supply.

\section{NUMERICAL APPLICATION}

s practical application, to illustrate the reliability analysis of an elevated tank, this application considers a RC water tank with a capacity of $1000 \mathrm{~m}^{3}$ elevated pedestal (Fig. 8). This structure is located on a soft soil, called $S_{3}$ type, by the Algerian seismic code. The geometrical characteristics of the elevated tank are summarized in Tab. 3 [1].

\begin{tabular}{lcc}
\hline Internal diameter of the tank container & 14.00 & $\mathrm{~m}$ \\
Average height of water in the tank container & 7.25 & $\mathrm{~m}$ \\
Height of the tank supporting system (Piles) & 24.60 & $\mathrm{~m}$ \\
Number of columns & 12 & \\
Dimensions of the columns & $0.80 \times 0.80$ & $\mathrm{~m}^{2}$ \\
\hline
\end{tabular}

Table 3: Geometrical characteristics of the elevated tank.

\section{Response spectrum}

The seismic acceleration imposed on the tank, taking into account it's interaction with the ground, is obtained from the dimensioning spectrum as a function of the seismic zone and the period $\mathrm{T}$ according to the Algerian seismic code [37], as shown in Fig. 9. 


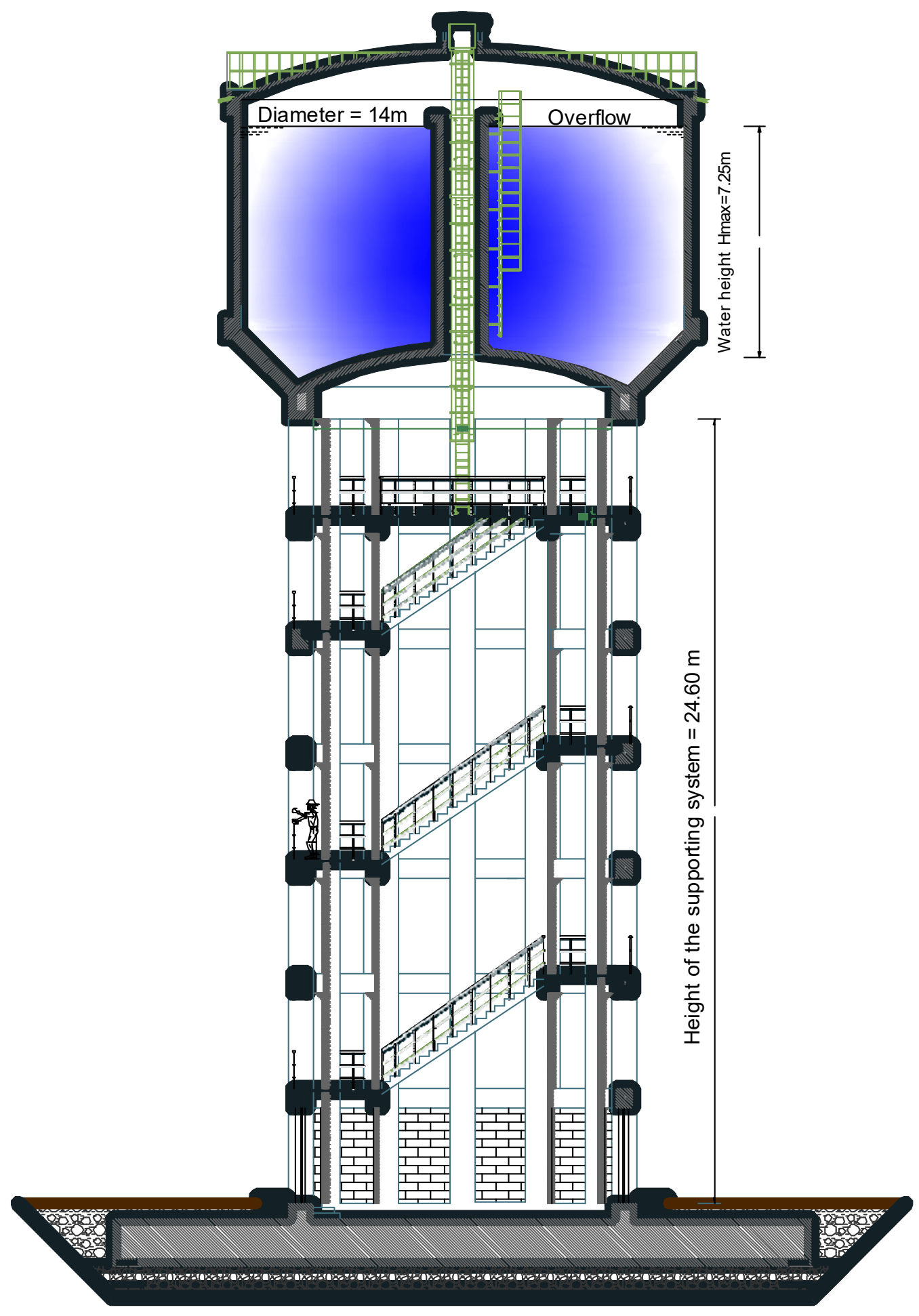

Figure 8: Longitudinal cross of the elevated tank [1].

Failure probability assessment of an elevated tank

The analytical assessment of the failure probability of a storage tank from the Eqn.6 is impossible. Several numerical approaches based on numerical approximations are proposed in the literature [8] such as Monte Carlo method, First Order Reliability Method (FORM) and the Second Order Reliability Method (SORM). In this work, Monte Carlo simulation is used to estimate the failure probability $P_{f}$ for its simplicity, and because it is considered as the more robust approach for the evaluation of the failure probability . The principle of this method is based on the generation of a large number of random samples noted $\mathrm{N}_{\text {sim. }}$. In this work, the pseudo-random number generator of Matlab ${ }^{\circledR}$ [32] software is used. 


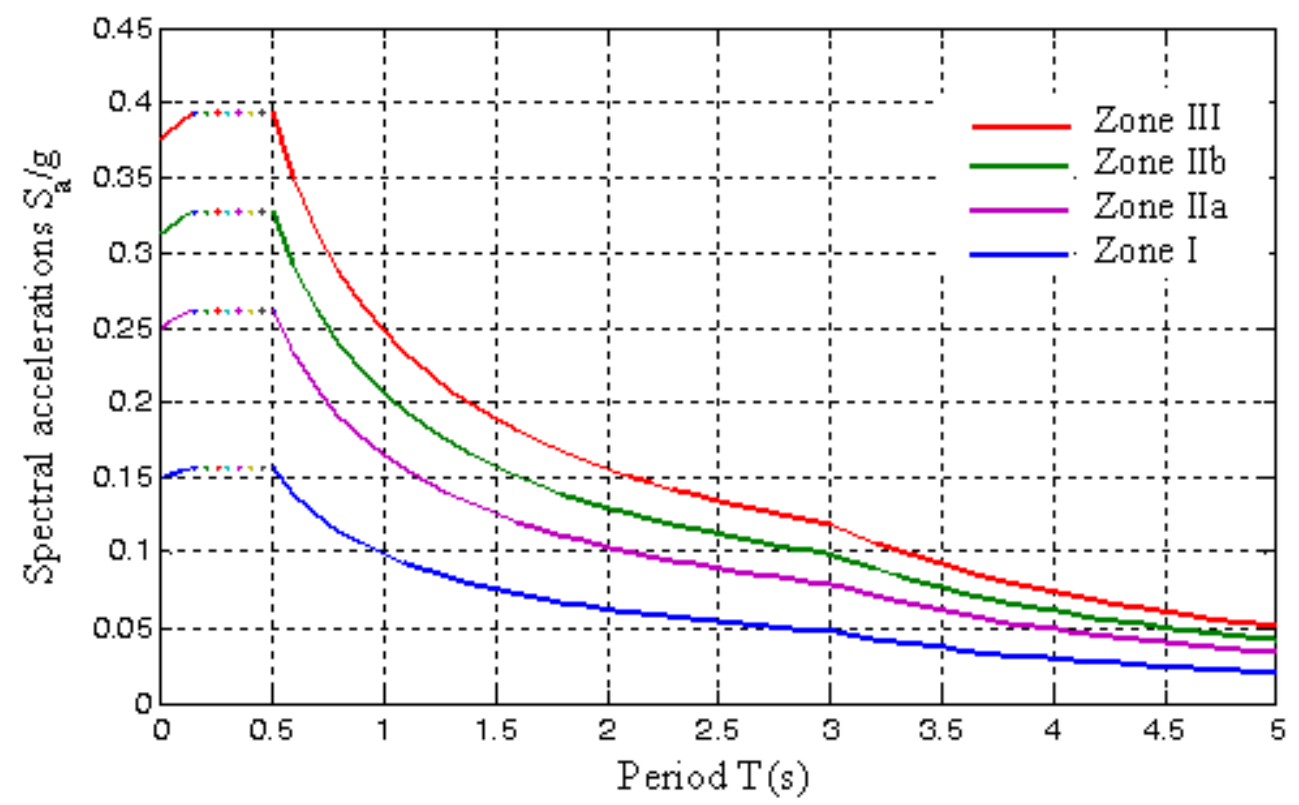

Figure 9: Response spectra for the different seismic zones.

Thus, a failure indicator $\mathrm{I}_{\mathrm{G}}$ is used to define the state of failure for a given limit state function; such as:

$$
I_{G \leq 0}=\left\{\begin{array}{l}
1 \text { if } G \leq 0 \\
0 \text { if } G>0
\end{array}\right.
$$

The failure probability is given, for each failure mode, by the following relation:

$$
\mathrm{P}_{f}=\frac{\sum_{1}^{\mathrm{N} s i m} \mathrm{I}_{\mathrm{G} \leq 0}}{\mathrm{~N}_{\operatorname{sim}}}
$$

\section{Statistical parameters of the random variable}

The peak ground acceleration $S_{a}$ is considered as a random variable, with statistical parameters, as given in Tab. 4. The Gumbel probability distribution is adopted, where is the best probability function that fit the measured accelerations. The coefficient of variation is given as the relationship between the mean value and the standard deviation estimated in the statistical analysis performed in the section (3.3.1).

$$
\mathrm{CV}=\frac{\sigma}{\mu}=\frac{1.497}{2.254}=0.664
$$

However, for the reliability analysis of the water tank; the recommended value of the seismic zone of the Algerian seismic code is considered as the mean value of the random variable with coefficient of variation of 0.664 .

\begin{tabular}{clllc}
\hline $\begin{array}{c}\text { Random } \\
\text { variable }\end{array}$ & Distribution law & $\begin{array}{c}\text { Average value of the coefficient } \\
\text { (A) of the zone }\end{array}$ & $\begin{array}{r}\text { Coefficient of } \\
\text { variation CV }\end{array}$ \\
& Low seismicity (zone I) & 0.12 & \\
\multirow{2}{*}{$\mathrm{S}_{\mathrm{a}}$} & Medium seismicity (zone IIa) & 0.20 & 0.664 \\
& \multirow{2}{*}{ Gumbel } & High seismicity (zone IIb) & 0.25 & \\
& & Very high seismicity (zone III) & 0.30 & \\
\hline
\end{tabular}

Table 4: Parameters of the generation of the random variable Sa. 
To ensure the accuracy of the estimation of the probability of failure obtained with Monte Carlo simulations, convergence tests were performed for different limit state functions as shown in Fig.10.These results show that the convergence and the stability of estimation of $P_{f}$ value are obtained from a number of simulations equal to $4.10^{5}$. Therefore, the number 5.105is used to generate Monte Carlo samples.

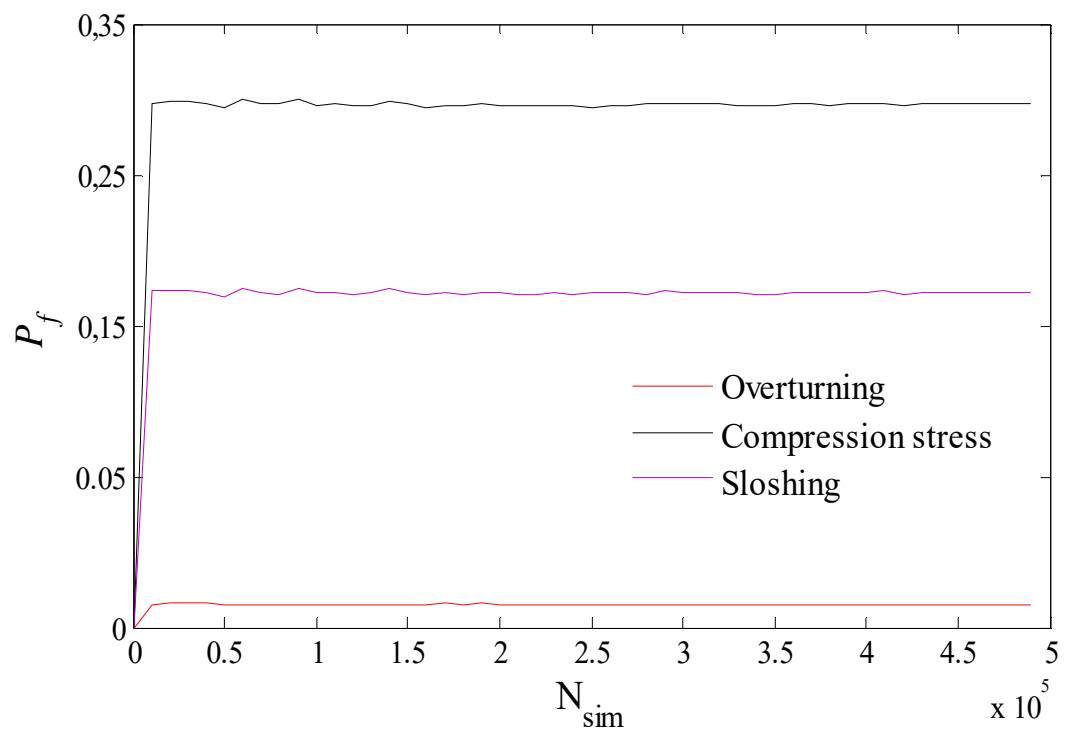

Figure 10: Convergence and stability of probability of failure $\mathrm{P}_{f}$ with respect to the number of simulations.

Evolution of the failure probability regarding to the water height in the container

Figs. 11 to 13 show the evolution of the failure probability for the following failure modes: overturning, compression stress and sloshing, as a function to the water height in the tank and the different seismic zones.

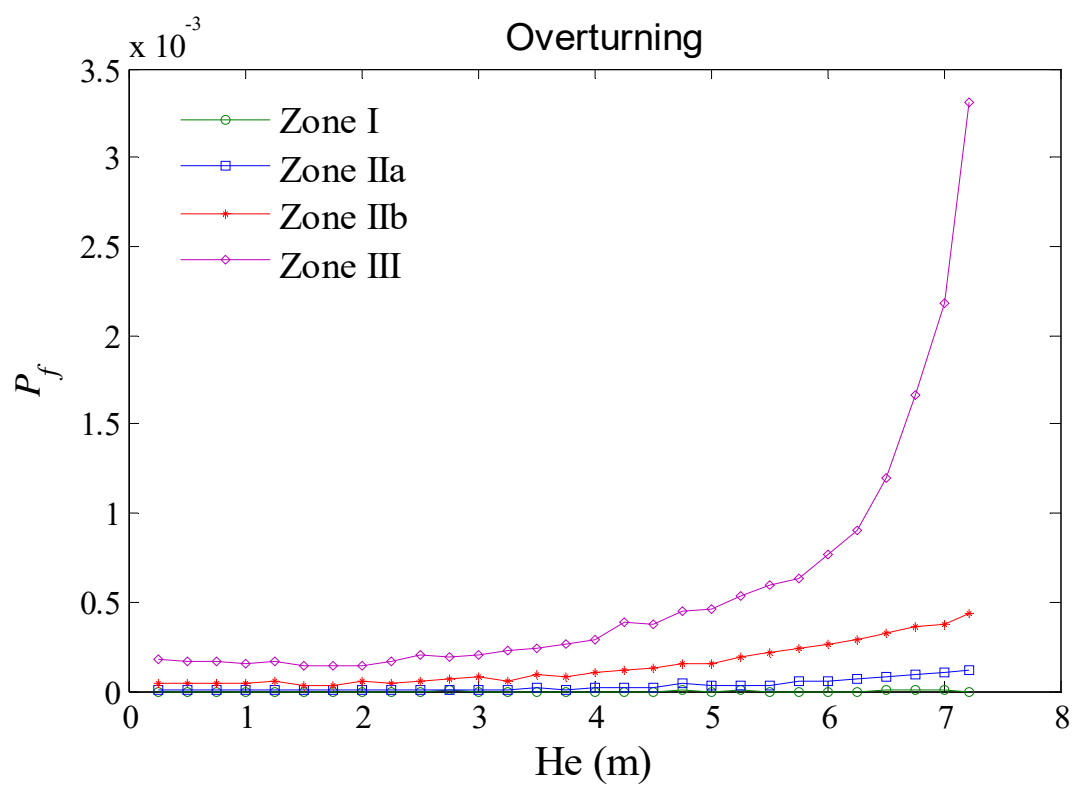

Figure 11: Failure probability as a function of water height in the overturning failure mode.

The failure probability is very small $\left(<10^{-8}\right)$ for sliding and traction failure mode regarding the water height in the tank container and the seismic zone, thus it can be considered insignificant. However, Fig. 13 shows that the failure probability of the sloshing failure mode is insignificant, except when the water height approaches the level of the overflow (about $50 \mathrm{~cm}$ ). In other words, the sloshing failure mode appears when the water height in the tank is at its maximum level. Moreover, this situation leads to a high failure probability for the high and very high seismic zones, where the probability of failure exceeds the admissible values for a civil engineering structure, which should be lower than the admissible value of $10^{-3}$ [26]. For compression stress and overturning failure modes, the failure probability increases with respect to the water height and the seismic zone. Tab. 5 gives the maximum values of the failure probability $P_{f-\max }$ regarding of the seismic zone and for a water height equal to $50 \%$ of $\mathrm{H}_{\max }$. These results demonstrate 
that there is less risk of ruin by overturning failure mode for all the seismic zones, when the water height in the tank is equal to $50 \%$ of $\mathrm{H}_{\max }$. However, for the compression stress failure mode, a high risk of failure is observed in the very high seismic zone, where the failure probability exceeds the admissible value.

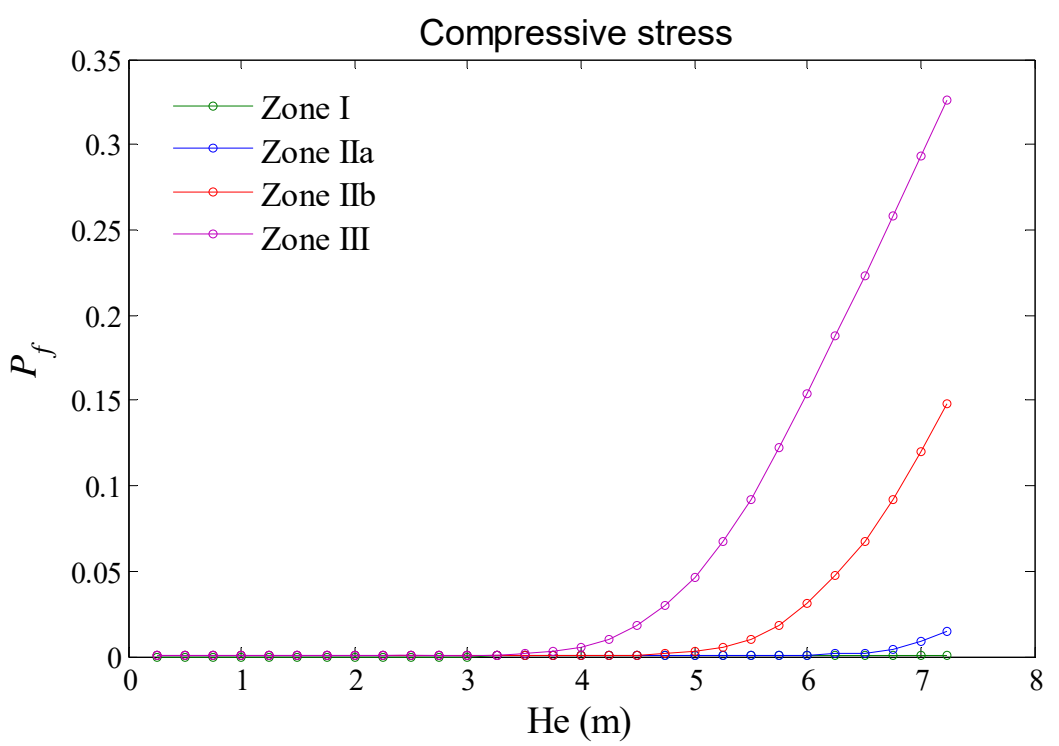

Figure 12: Failure probability as a function of water height in the compression stress failure mode.

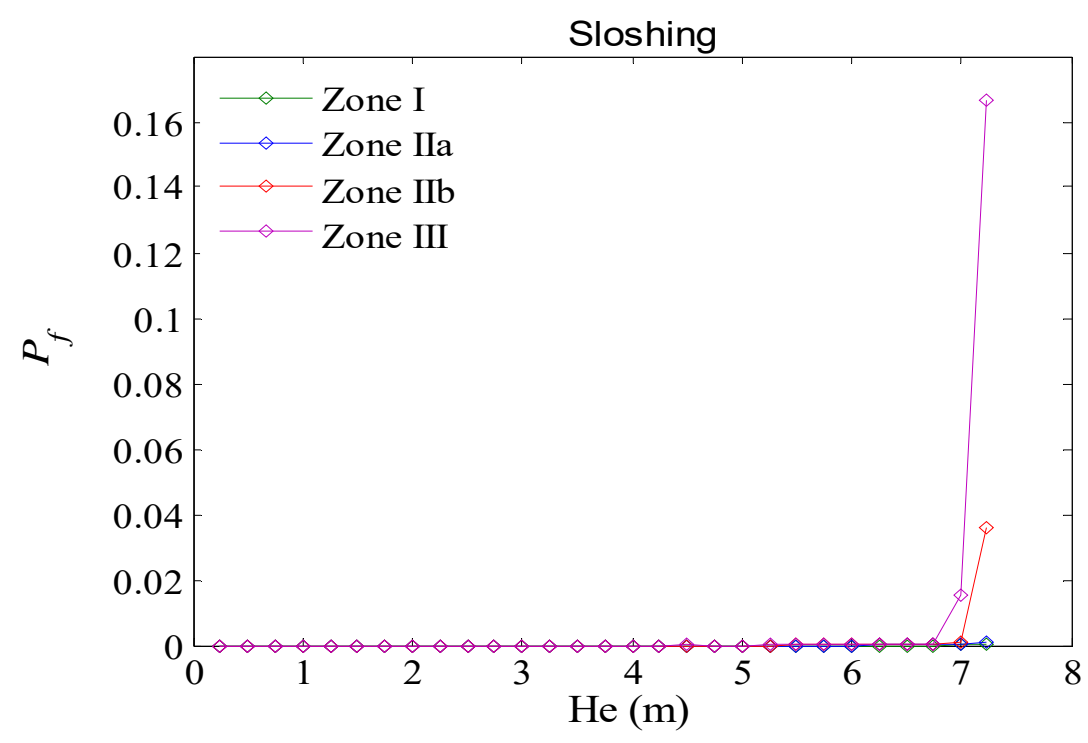

Figure 13: Failure probability as a function of water height in the sloshing failure mode.

\begin{tabular}{|c|c|c|c|c|c|}
\hline & Seismic zone & Compression & Overturning & $P_{\text {fadmissible }}$ & Observation \\
\hline \multirow{4}{*}{$P_{f-\max }$} & Zone I & $210^{-6}$ & $1.10^{-6}$ & \multirow{4}{*}{$10^{-8}<P_{f}<10^{-3}$} & Acceptable \\
\hline & Zone IIa & $1.0810^{-4}$ & $1,2.10^{-5}$ & & Acceptable \\
\hline & Zone IIb & $4.0210^{-4}$ & $7,6.10^{-5}$ & & Acceptable \\
\hline & Zone III & $2.7710^{-3}$ & $2,67.10^{-4}$ & & Unacceptable \\
\hline
\end{tabular}

Table 5: Failure probability $P_{f \max }$ as a function of seismic zones, for $\mathrm{H}_{\mathrm{e}}=50 \%$ of $\mathrm{H}_{\max }$.

Besides, when the water height in the tank reaches the maximum height, the concrete crushing failure mode due to the compression of the supporting system is the most critical failure mode for the different seismic zones (Tab. 6). We can notice that the failure probability exceeds the admissible value of the medium, high and the very high seismic zones. The second most critical limit state function is the sloshing failure mode, whose the failure probability exceeds also the admissible value of the high and the very high seismic zones. The third critical limit state function is the 
overturning failure mode, where the failure probability exceeds the admissible value only for the very high seismic zone.

\begin{tabular}{ccccccc}
\hline & Seismic zone & Compression & Sloshing & Overturning & $P_{\text {fadmissible }}$ & Observation \\
$P_{f \max }$ & Zone I & $1.0210^{-4}$ & $810^{-6}$ & $210^{-6}$ & & Acceptable \\
& Zone IIa & $1.51510^{-2}$ & $9.6910^{-4}$ & $1.1410^{-4}$ & $10^{-8}<P_{f}<10^{-3}$ & Unacceptable \\
& Zone IIb & 0.1475 & $3.6010^{-2}$ & $4.410^{-4}$ & & Unacceptable \\
& Zone III & 0.326 & 0.166 & $3.310^{-3}$ & Unacceptable \\
\hline
\end{tabular}

Table 6: Failure probability $P_{f-\max }$ with respect to seismic zones and for $\mathrm{H}_{\mathrm{e}}=\mathrm{H}_{\max }$.

The site effect on the evolution of $P_{f}$

To consider the influence of the structural foundation site on the probability failure, an analysis is performed with respect to the site effect for each failure mode considering the tank located in the high seismic zone. Figs. 14 to 16 show the failure probability as a function of the water height in the container and the site effect.

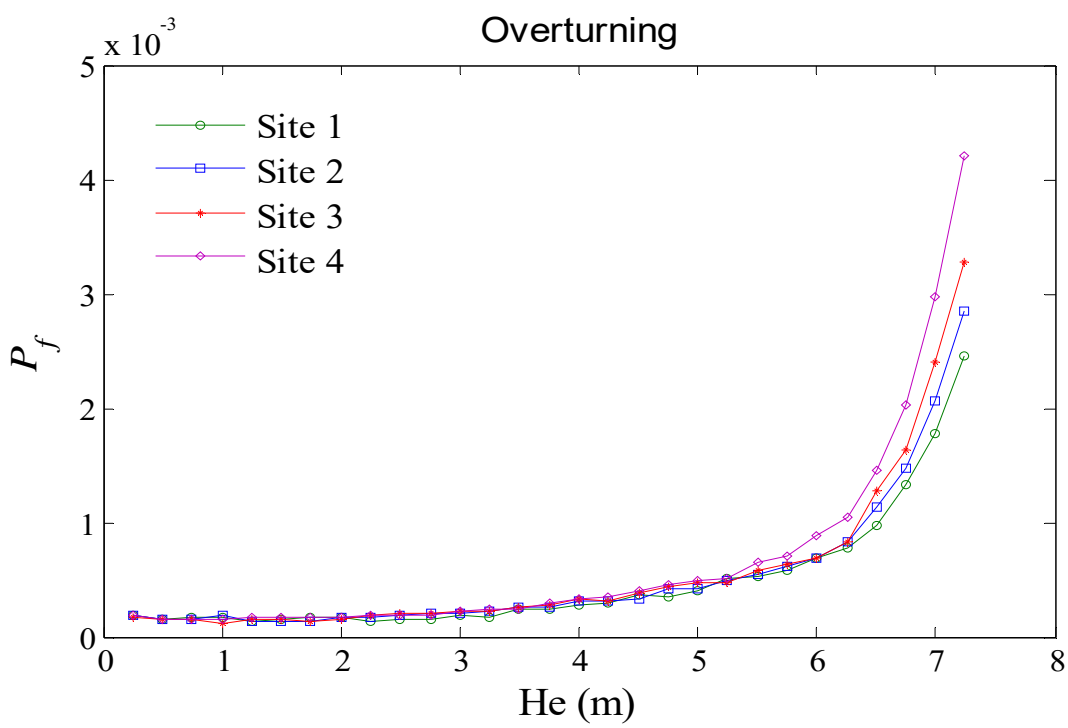

Figure 14: Evolution of failure probability of the overturning failure mode with respect to the water height and the site effect.

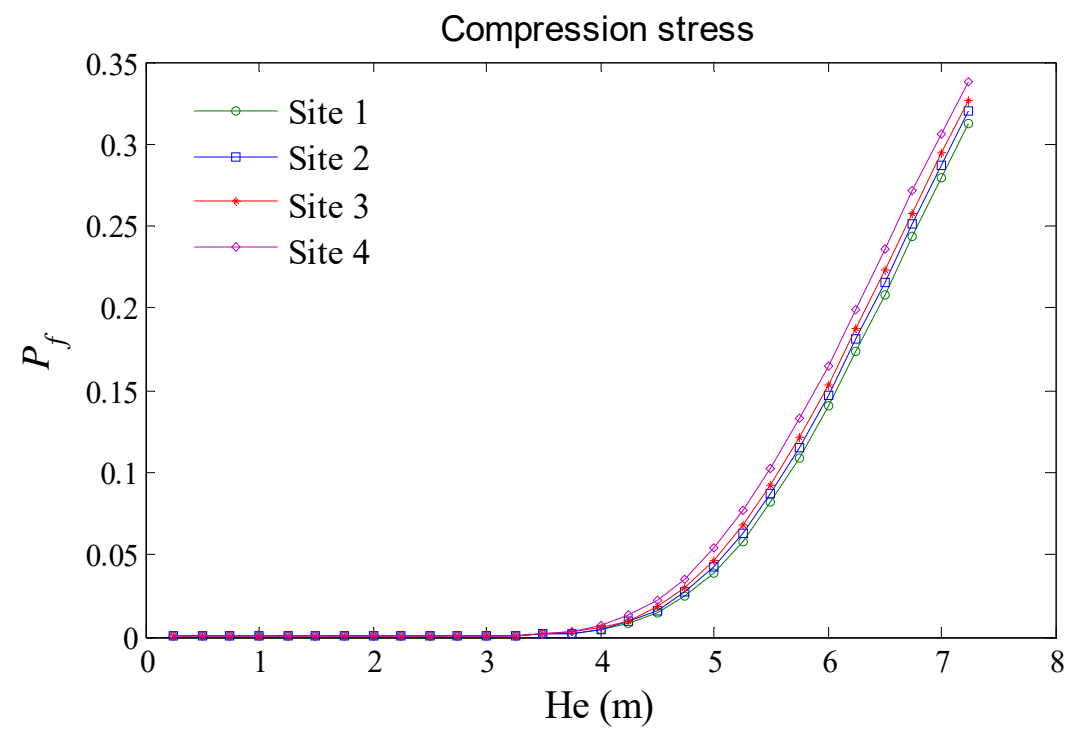

Figure 15: Evolution of failure probability of the compression stresses failure mode with respect to the water height and the site effect. 


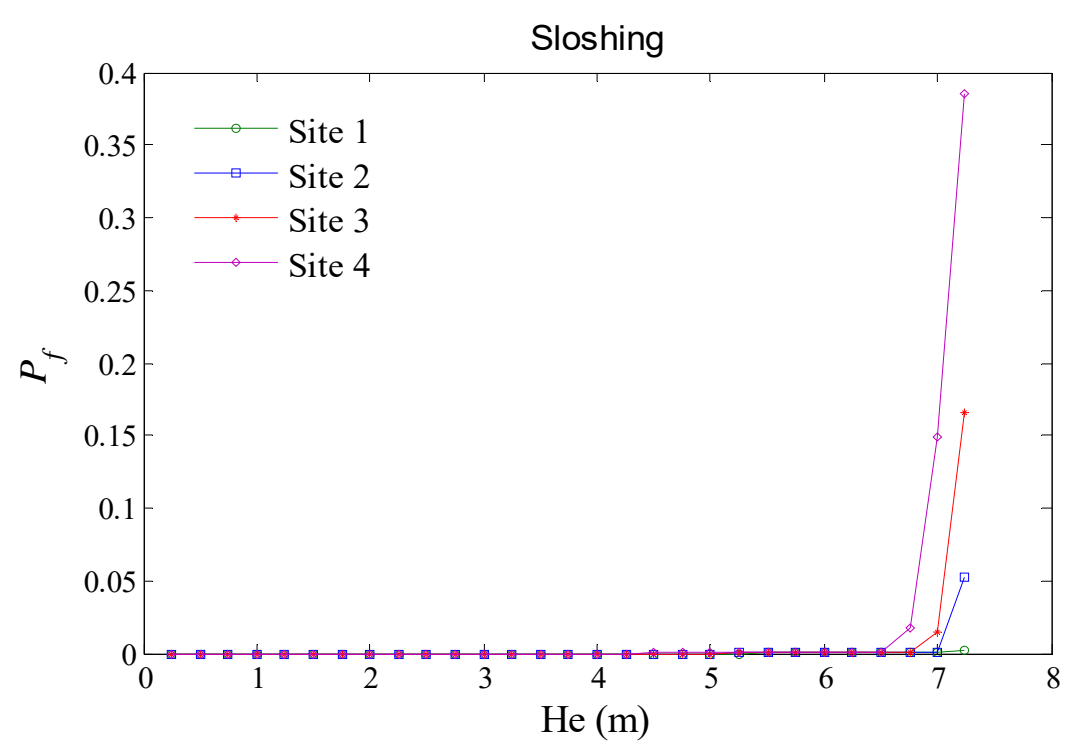

Figure 16: Evolution of failure probability of the sloshing failure mode with respect to the water height and the site effect.

The failure risk by sloshing failure mode becomes more important when the water height in the tank container reaches its maximum level. Tab. 7 shows that the failure probability by sloshing exceeds the admissible value for all soil types. As for compression and overturning failure modes, the failure probability increases with water height in the tank container and the soil types, from the soil type $\mathrm{S}_{1}$ (rocky) to the soil type $\mathrm{S}_{4}$ (very soft).

The results in Tab. 7 and Tab. 8 show that for all the different soil types, the failure mode by concrete crushing with compression of the supporting system is the most critical failure mode, followed by the overturning failure mode. The failure probability values exceed the admissible value for all the different soil types.

\begin{tabular}{ccccccc}
\hline & Sol type & Compression & Sloshing & Overturning & $P_{\text {fadmissible }}$ & Observation \\
\hline \multirow{3}{*}{$P_{f-\max } \quad{\text { Site } \mathrm{S}_{1}}$} & 0.3120 & $2.6310^{-3}$ & $2.4510^{-3}$ & & Unacceptable \\
& Site $\mathrm{S}_{2}$ & 0.3205 & $5.210^{-2}$ & $2.8410^{-3}$ & & Unacceptable \\
& Site $\mathrm{S}_{3}$ & 0.3260 & 0.1660 & $3.2710^{-3}$ & & Unacceptable \\
& Site $\mathrm{S}_{4}$ & 0.3370 & 0.3851 & $4.20710^{-3}$ & & Unacceptable \\
\hline
\end{tabular}

Table 7: Failure probability $P_{f-\max }$ as a function soil types, for $\mathrm{H}_{\mathrm{e}}=\mathrm{H}_{\max }$.

\begin{tabular}{|c|c|c|c|c|c|}
\hline \multirow{5}{*}{$P_{f \max }$} & Sol type & Compression & Overturning & $P_{\text {fadmissible }}$ & Observation \\
\hline & Site $S_{1}$ & $3.4310^{-3}$ & $2.4810^{-4}$ & \multirow{4}{*}{$10^{-8}<P_{f}<10^{-3}$} & Unacceptable \\
\hline & Site $S_{2}$ & $2.7310^{-3}$ & $2.6010^{-4}$ & & Unacceptable \\
\hline & Site $\mathrm{S}_{3}$ & $2.4810^{-3}$ & $2.8410^{-4}$ & & Unacceptable \\
\hline & Site $S_{4}$ & $2.1910^{-3}$ & $2.8810^{-4}$ & & Unacceptable \\
\hline
\end{tabular}

Table 8: Failure probability $P_{f-m a x}$ as a function soil types, for $\mathrm{H}_{\mathrm{e}}=50 \%$ of $\mathrm{H}_{\max }$.

\section{Fragility curves}

Figs. 17 to 19 give the 2D and 3D fragility curves of the probability of failure with respect to the soil types and the seismic zones. In this analysis, we assume that the tank is filled until the overflow, where this situation is more damaging for the structure. These fragility curves highlight that the failure probability increases with the seismic acceleration (seismic zone) for the same site. For a given seismic zone, this failure probability worse with the soil types, where it increases starting from the soil type $\mathrm{S}_{1}$ (rock soil) to the soil type $\mathrm{S}_{4}$ (soft soil). 
Compression stress
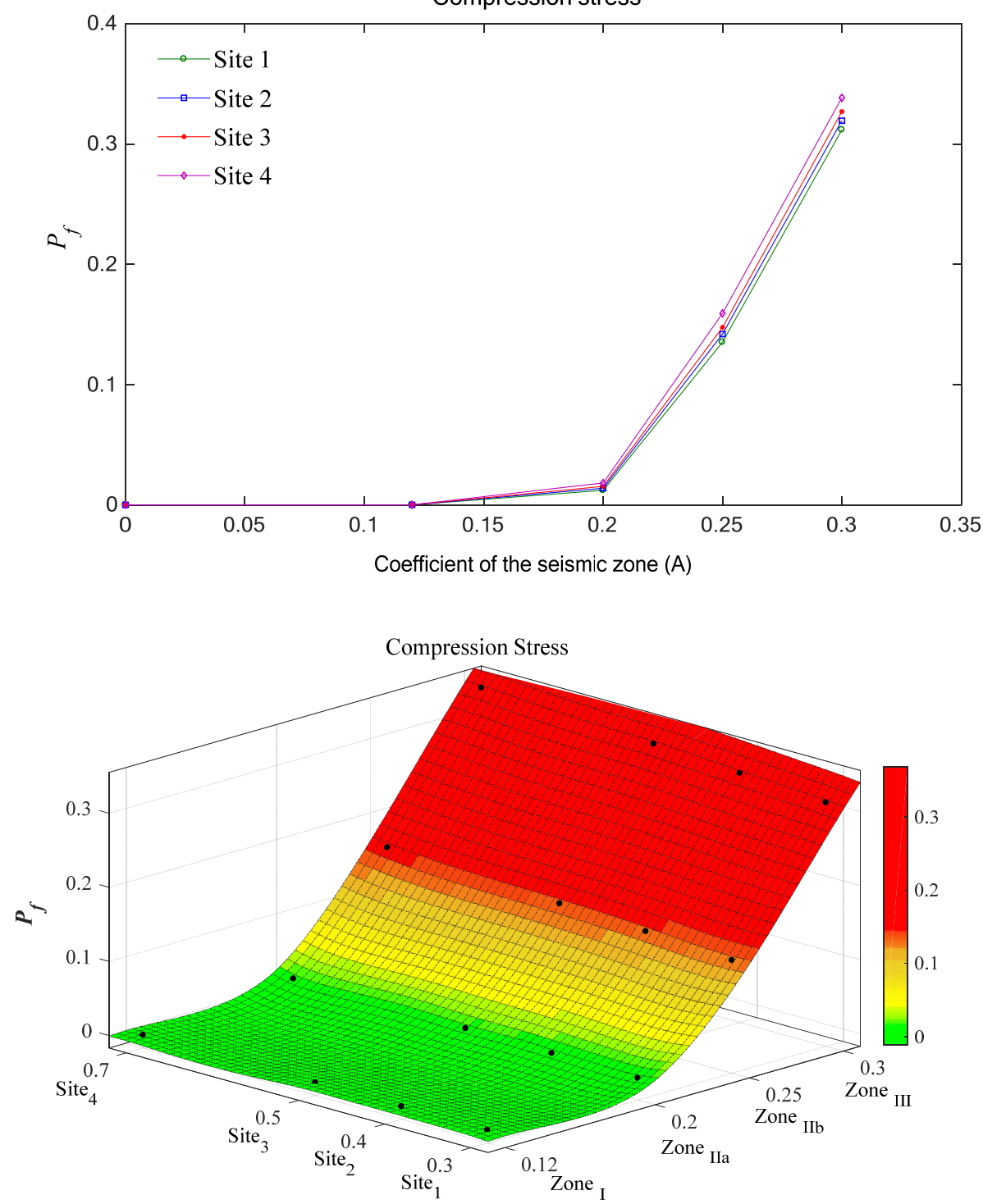

Figure 17: Fragility curves of the compression stress failure mode.

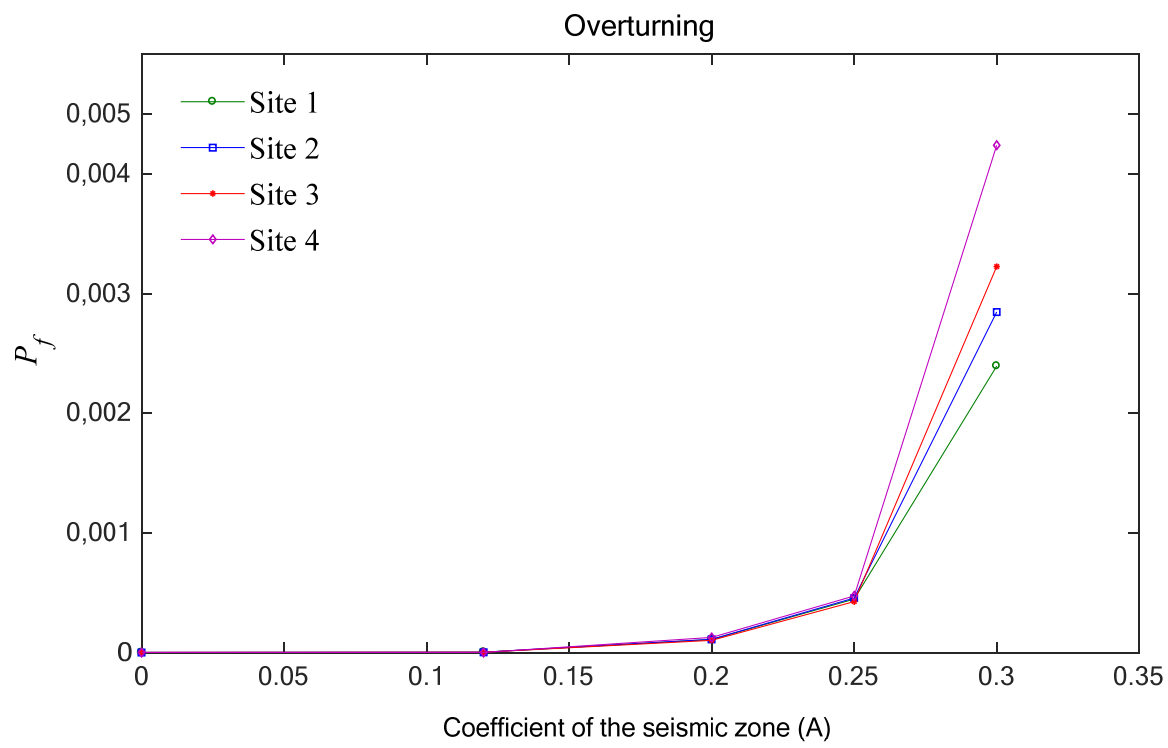




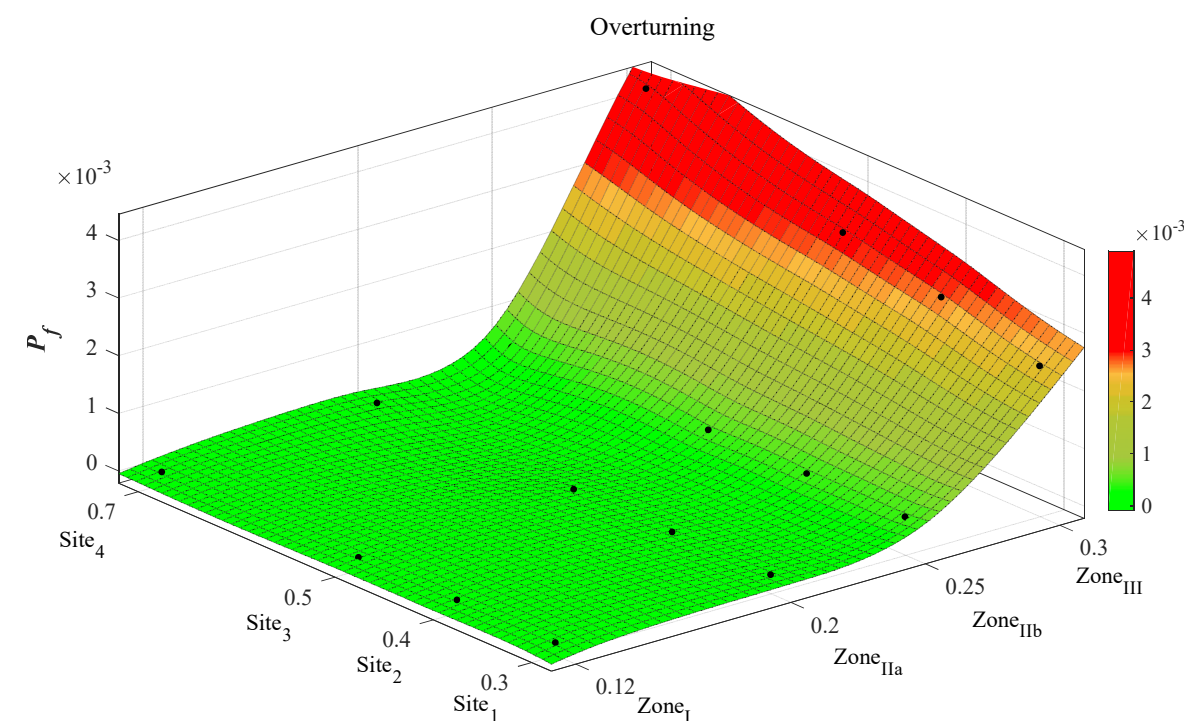

Figure 18: Fragility curves of the overturning failure mode.
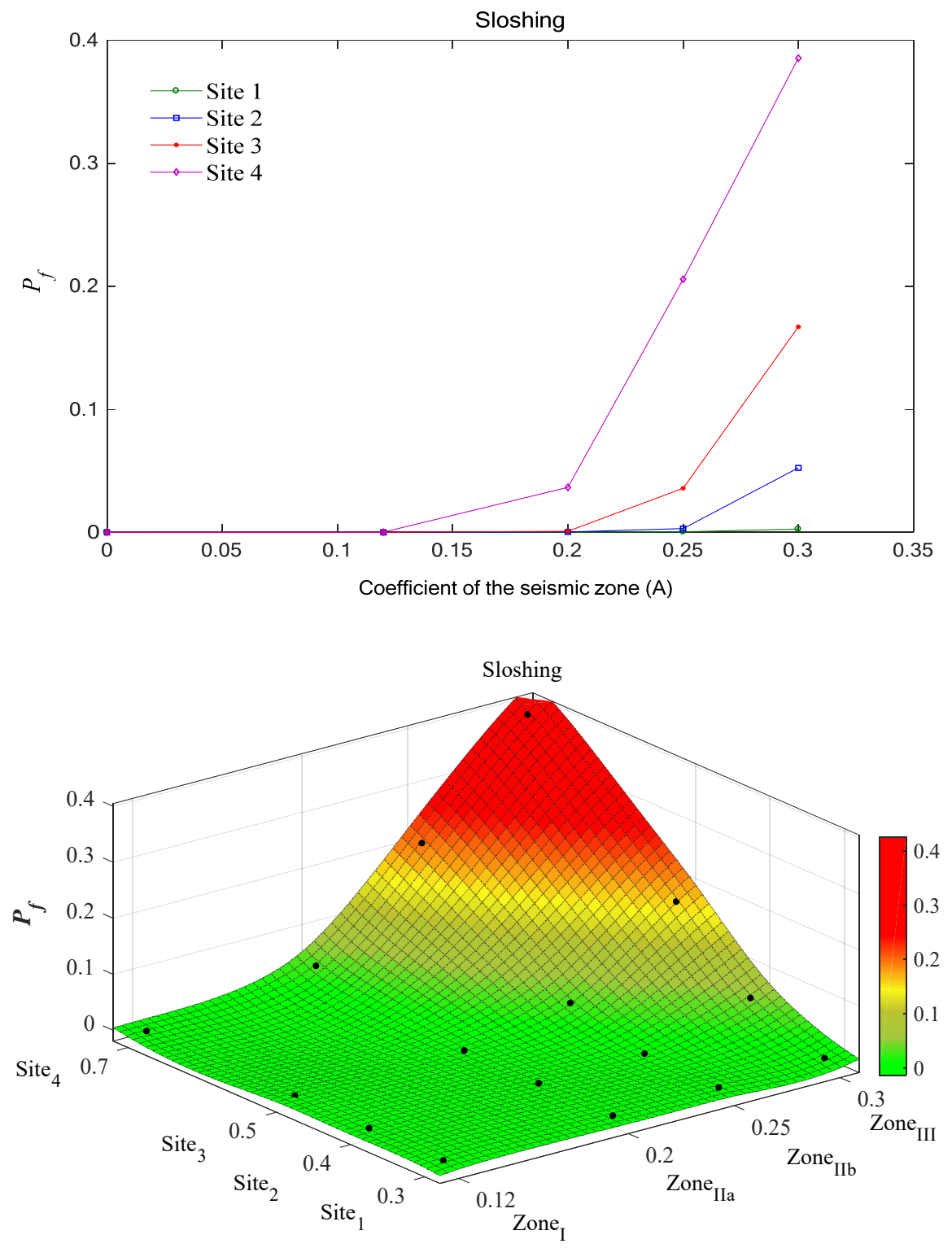

Figure 19: Fragility curves of the sloshing failure mode. 
Evolution of failure probability as a function of time

Figs. 20 to 22 show the evolution of the failure probability at different moments of the day, for different failure modes and different seismic zones. It appears that the failure probability is insignificant for sliding and traction failure modes at any time of the day. However, the failure probability of overturning and compression failure modes increases highly with respect to the seismic zone in the time slot from midnight to $9 \mathrm{am}$, corresponding to hours when the water height in the container tank is more than $50 \%$ of $\mathrm{H}_{\max }$. The risk of failure by sloshing is observed for the very high seismicity zone (zone III) and high seismicity zone (zone IIb), mainly when the water height reaches the overflow in the tank container corresponding to the time period from 6 am to $7 \mathrm{am}$. In fact, the water consumption is the lowest during this time period (the tank stores more than it distributes). The risk of failure by concrete compression failure mode is more critical especially for very high seismic zone, when the water height is equal or greater than $50 \%$ of $\mathrm{H}_{\max }$, corresponding to the time slot from midnight to $9 \mathrm{am}$.

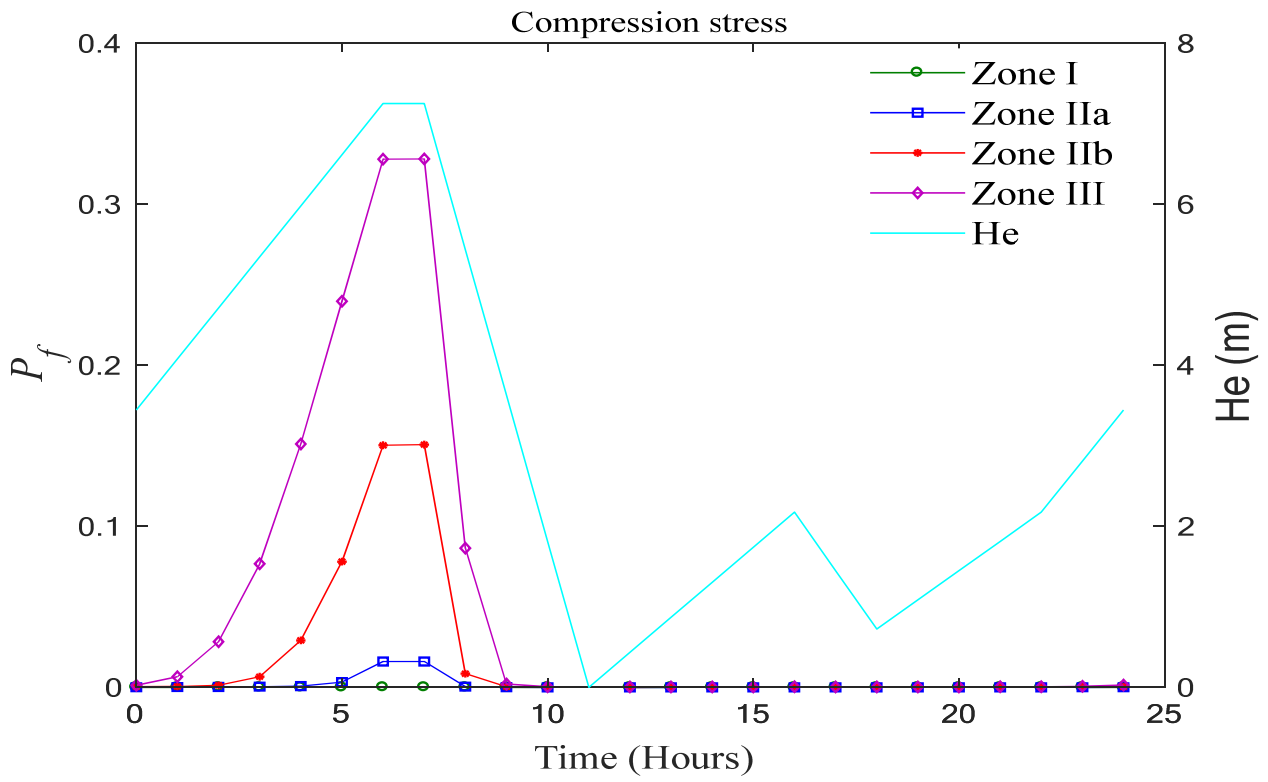

Figure 20: Evolution of the failure probability $P_{f}$ as a function of time for the compression stress failure mode.

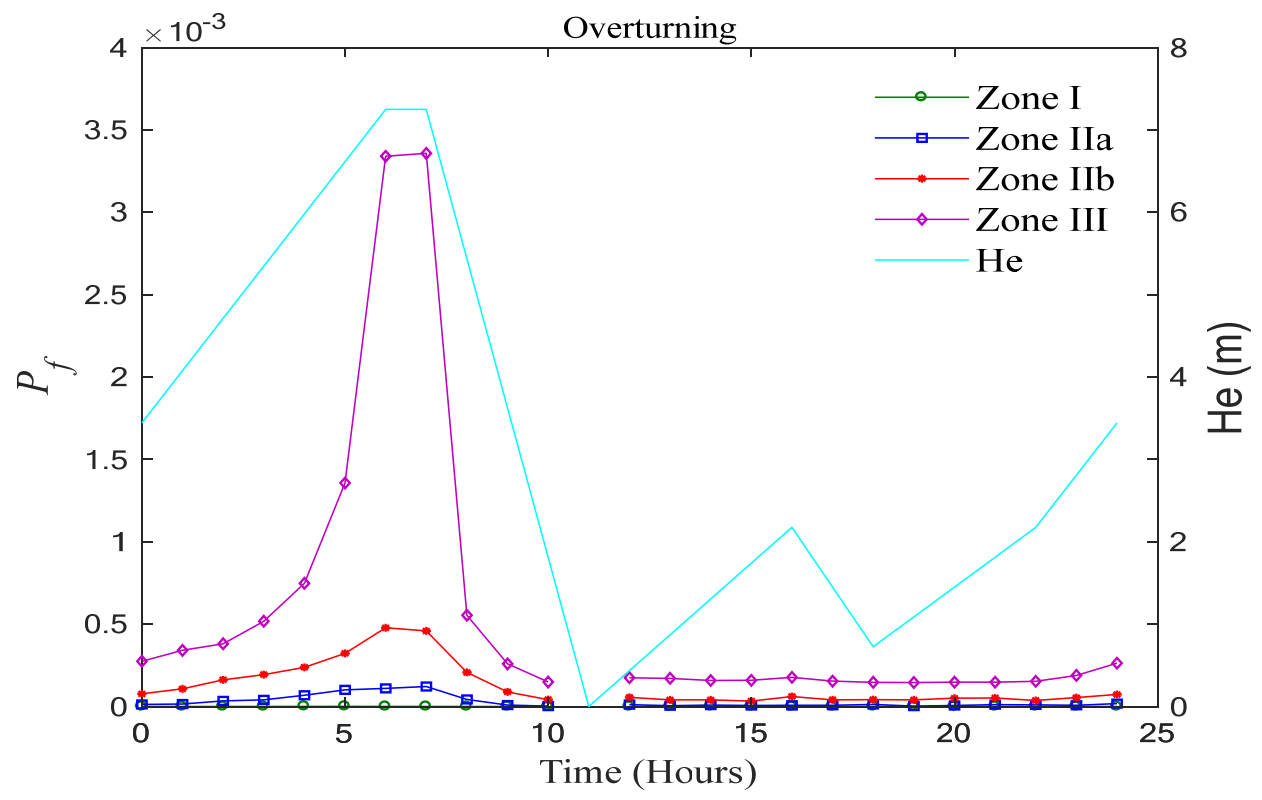

Figure 21: Evolution of the failure probability $P_{f}$ as a function of time for the overturning failure mode. 


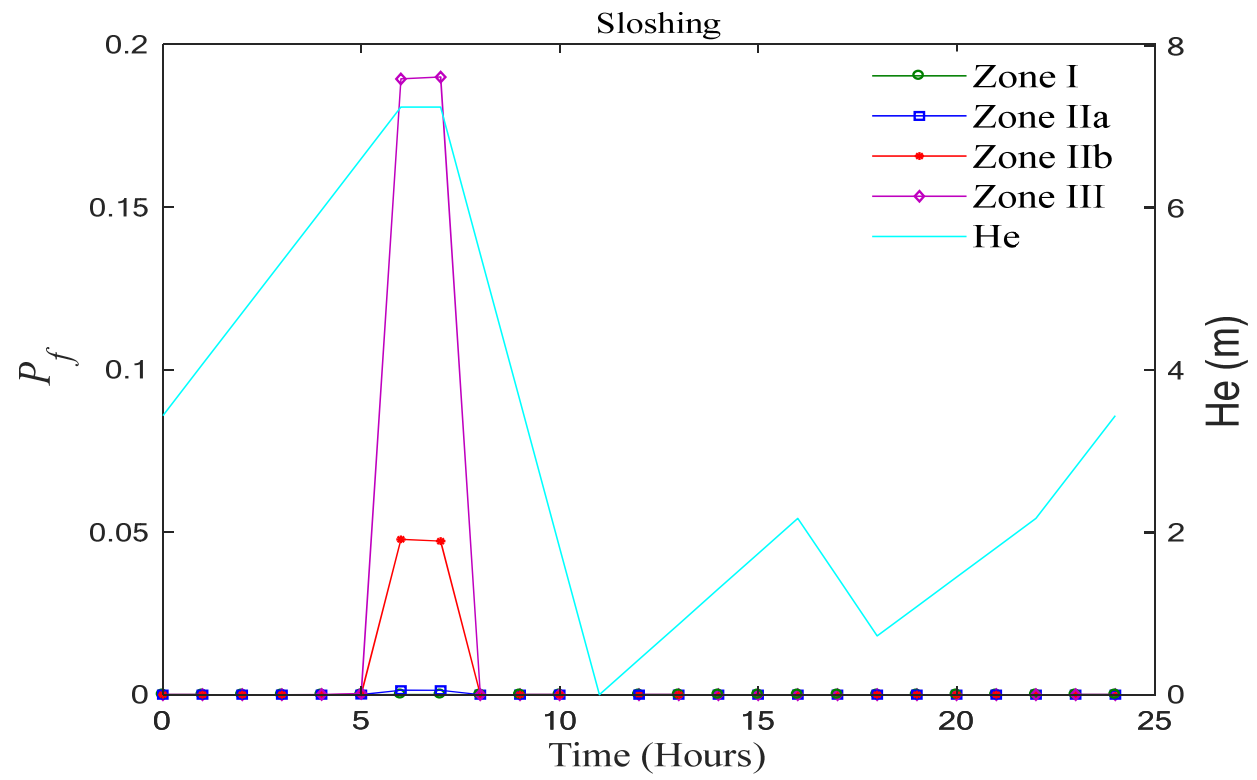

Figure 22: Evolution of the failure probability $P_{f}$ as a function of time for the sloshing failure mode.

The risk of failure by sliding and traction is insignificant, whatever the seismic zone and the soil types. Consequently, the seismic zone effect and the soil types have an insignificant influence on these failure modes at any time of the day. The failure mode by sloshing is observed only when the water height is close to the overflow. This risk of failure is influenced by the seismic zone acceleration and is worsened by the soil types. The structural failure by sloshing is highlighted for the high and very high seismic zone, which is increased by considering the soil types $\mathrm{S}_{4}$ and $\mathrm{S}_{3}$.

The risk of failure by overturning failure mode remains in the same proportion for the same seismic zone whatever the water height in the tank container. Probability of failure remains lower than the admissible value. The elevated tank failure by overturning failure mode is observed for high seismic zone and for a water height corresponding to the overflow in the tank container. Unquestionably, the failure mode by concrete compression remains the most critical state function for an elevated tank. This risk of failure increases with respect of water height and then aggravated by the seismic zones and the soil type.

This study shows that the elevated tank is vulnerable in the time slot from midnight to 9 am in medium, high and very high seismic zone, where the structural failure is more important for softer soil (ground types $S_{3}$ and $S_{4}$ ).

\section{CONCLUSION}

$\mathrm{T}$ he influence of the seismicity level on the failure probability has been highlighted by the fragility curves. We were able to demonstrate that the most prejudicial failure mode of the elevated tank is the compression of the supporting system when the container is filled to less than $50 \%$ of its maximum capacity. The most prejudicial failure mode is the sloshing mode when the water height in the container is near of the overflow level. The failure risk of the structure reaches a maximum value while the drinking water network is the least requested by subscribers. During this time slot, where the tank stores the maximum capacity, the cover dome can be damaged under the wave's effect created by the seismic action. We can conclude that the Algerian seismic code must more consider this problem of sloshing by proposing a relation that allows estimating a practical height of freeboard.

The analysed tank in this study has been the subject of a deterministic analysis [1], whose safety factors were found higher than those required by the dimensioning codes, while our analysis has shown the low level of its reliability. We can conclude that, faced to the complexity of the hydrodynamic behaviour of elevated tanks, the consideration in engineering calculations; during the design stage in the engineering offices; of the uncertainties by reliability analysis is essential today to better understand the failure risks.

\section{ACKNOWLEDGMENTS}

he authors present their thanks to African Geosystem Company of Algiers (http://www.agc-dz.com) for the provided documentation (numerical application). The authors wish to thank the Algerian Ministry of higher education and scientific research for funding the University education research project (PRFU - N A01L02UN150120180002) and Tassili Project 
(PHC - 18MDU121).

\section{DECLARATION OF INTEREST STATEMENT}

$\mathrm{n}$ behalf of all authors, the corresponding author states that there is no conflict of interest.

\section{REFERENCES}

[1] AGC-Egis (2014). Etude d'exécution d'un réservoirs surélevé circulaire en béton de capacité $1000 \mathrm{~m}^{3}$ de la ville de Menea. Rapprot interne. Algerie.

[2] Ahmadi, H., Mohammadi, A. H.and Yeganeh, A.(2015). Probability density functions of SCFs in internally ringstiffened tubular KT-joints of offshore structures subjected to axial loading, Thin-Walled Struct., 94, pp. 485-499. DOI: $10.1016 /$ j.tws.2015.05.012.

[3] Akbari, J., Salami, O.and Isari, M.(2020). Numerical Investigation of the Seismic Behavior of Unanchored Steel Tanks with an emphasis on the Uplift Phenomenon, Frat. ed Integrita Strutt., 14(53), pp.92-105. DOI: 10.3221/IGF-ESIS.53.08

[4] Aliche, A., Hammoum, H.and Bouzelha, K.(2019). Mecano-reliability analysis applied to RC tank under seismic loads according to the Algerian seismic standard, Asian. J. Civ. Eng., 20(3) pp. 395-408.

DOI: $10.1007 /$ s42107-018-00113-x.

[5] Berhaman, F.and Behnamfar, F.(2009). Probabilistic seismic demand model and fragility estimates for critical failure modes of un-anchored stel storage tanks in petroleum complexes, Probab. Eng. Mech., 24, pp. 527-536. DOI: $10.1016 /$ j.probengmech.2009.03.005.

[6] CEN, E.(2006). 8: Design of structures for earthquake resistance-Part 4: silos, tanks and pipelines, C. E. N.

[7] Davidovici, V.and Haddadi, A.(1982). Calcul pratique de réservoirs en zone sismique, Ann. Inst. Tech. Batim. Trav. Publics. 409

[8] Ditlevsen, O. and Madsen, H. O. (1996).Structural reliability methods: Wiley New York.

[9] Dupont, A. (1981).Hydraulique urbaine: Hydrologie-captage et traitement des eaux: Eyrolles.

[10] Epstein, H. I.(1976). Seismic design of liquid-storage tanks, J. Struct. Div. 102(9), pp. 1659-1673.

[11] Fascicule 74 (1998). Construction des réservoirs en béton - cahier des clauses techniques générales, Ministère de l'équipement des transports et du logement.

[12] Gholizad, A., Golafshani, A. and Akrami, V.(2012). Structural reliability of offshore platforms considering fatigue damage and different failure scenarios, Ocean Eng., 46, pp. 1-8. DOI: 10.1016/j.oceaneng.2012.01.033.

[13] Graham, E.and Rodriquez, A.(1951). The characteristics of fuel motion which affect airplane dynamics. Douglas Aircraft Co Inc Santa Monica Ca.

[14] Hammoum, H., Bouzelha, K.and Slimani, D. (2016). Seismic risk of RC water storage elevated tanks: Case study, In: Handbook of materials failure analysis with case studies from the chemicals, concrete and power industries. Elsevier,pp.187-216. DOI:10.1016/B978-0-08-100116-5.00008-9.

[15] Haroun, M. A. (1980). Dynamic analyses of liquid storage tanks. California Institute of Technology.

[16] Haroun, M. A. (1983). Vibration studies and tests of liquid storage tanks, Earthquake Eng. Struct. Dyn., 11(2), pp. 179-206.

[17] Haroun, M. A.(1984). Stress analysis of rectangular walls under seismically induced hydrodynamic loads, Bull. Seismol. Soc. Am., 74(3), pp. 1031-1041.

[18] Haroun, M. A. and Badawi, H. S.(1988). Seismic behavior of unanchored ground-based cylindrical tanks, Proceedings 9th of the World Conference on Earthquake Engineeringdate.

[19] Haroun, M. A.and Ellaithy, H. M. (1985). Seismically induced fluid forces on elevated tanks, J. Tech. Top. Civ. Eng. 111(1), pp. 1-15.

[20] Hoskins, L. M.and Jacobsen, L. S. (1934). Water pressure in a tank caused by a simulated earthquake, Bull. Seismol. Soc. Am. 24(1), pp. 1-32.

[21] Housner, G. W. (1957). Dynamic pressures on accelerated fluid containers, Bull. Seismol. Soc. Am., 47(1), pp.1535.

[22] Housner, G. W. (1963). The dynamic behavior of water tanks, Bull. Seismol. Soc. Am., 53(2), pp. $381-387$.

[23] Hunt, B.and Priestley, N.(1978). Seismic water waves in a storage tank, Bull. Seismol. Soc. Am.;68(2)pp.:487-499.

[24] Jacobsen, L. S.(1949). Impulsive hydrodynamics of fluid inside a cylindrical tank and of fluid surrounding a cylindrical pier, Bull. Seismol. Soc. Am., 39(3), pp. 189-204. 
[25] Jacobsen, L. S.and Ayre, R. S.(1951). Hydrodynamic experiments with rigid cylindrical tanks subjected to transient motions, Bull. Seismol. Soc. Am., 41(4), pp. 313-346.

[26]JCSS, P. M. C.(2001). Joint Committee on Structural Safety, Zurich, Switzerland.

[27] Lemaire, M., Chateauneuf, A.and Mitteau, J.-C. (2009). Structural reliability: Wiley Online Library.

[28] Livaoglu, R.(2008). Investigation of seismic behavior of fluid-rectangular tank-soil/foundation systems in frequency domain, Soil Dyn. Earthquake Eng., 28(2), pp. 132-146. DOI: 10.1016/j.soildyn.2007.05.005.

[29] Livaoglu, R.and Dogangun, A. (2007). Effect of foundation embedment on seismic behavior of elevated tanks considering fluid-structure-soil interaction, Soil Dyn. Earthquake Eng., 27(9), pp. 855-863. DOI: 10.1016/j.soildyn.2007.01.008.

[30] Livaoğlu, R.and Doğangün, A. (2006). Simplified seismic analysis procedures for elevated tanks considering fluidstructure-soil interaction, J. Fluids Struct. 22(3), pp. 421-439. DOI: DOI: 10.1016/j.jfluidstructs.2005.12.004.

[31] Lupoi, A.and Callari, C.(2012). A probabilistic method for the seismic assessment of existing concrete gravity dams, Struct. Infrastruct. Eng. 8(10), pp. 985-998. DOI: 10.1080/15732479.2011.574819.

[32] MathWorks, I. (2005). MATLAB: the language of technical computing. Desktop tools and development environment, version 7: MathWorks.

[33] Möller, O. and Rubinstein, M. (1992). Reliability-based design of R/C water tank structures under seismic action, Earthquake Eng. Struct. Dyn., 21(8), pp. 665-678. DOI: 10.1002/eqe.4290210802.

[34] Park, J.-H., Koh, H. and Kim, J. (1992). Fluid-structure interaction analysis by a coupled boundary element-finite element method in time domain, Boundary element technology VII. pp. 227-243.

[35] Peyras, L., Carvajal, C., Felix, H., Bacconnet, C., Royet, P., Becue, J.-P. and Boissier, D.(2012). Probability-based assessment of dam safety using combined risk analysis and reliability methods-application to hazards studies, Eur. J. Environ. Civ. Eng. 16(7), pp. 795-817. DOI: 10.1080/19648189.2012.672200.

[36] Phan, H. N., Paolacci, F., Bursi, O. S. and Tondini, N. (2017). Seismic fragility analysis of elevated steel storage tanks supported by reinforced concrete columns, J. Loss. Prevention. Proc.47, pp. 57-65.

[37] RPA99, A. (2003). Règles Parasismiques Algériennes, D. T. R (CGS).

[38] Ruge, A. C. (1938). Earthquake Resistance of Elevated Water-Tanks, Trans. Am.Soc.Civ. Eng., 103(1), pp. 889938.

[39] Sani, J., Nwadiogbu, C. and Yisa, G.(2014). Reliability Analysis of an Underground Reinforced Concrete Rectangular Water Tank, IOSR- J. Mech. Civ. Eng. 11(1), pp. 58-68.

[40] Sezen, H., Livaoglu, R. and Dogangun, A.(2008). Dynamic analysis and seismic performance evaluation of aboveground liquid-containing tanks, Eng. Struct. 30(3), pp.794-803. DOI: 10.1016/j.engstruct.2007.05.002.

[41] Werner, P. W. and Sundquist, K.(1949). On hydrodynamic earthquake effects, E. O. S. Trans. Am. Geo. Uni. 30(5), pp. 636-657.

[42] Westergaard, H. M.(1933). Water pressures on dams during earthquakes, Trans. Am.Soc.Civ. Eng. 98(2), pp.418433. 